NBER WORKING PAPER SERIES

\title{
HOW DO HOSPITALS RESPOND TO NEGATIVE FINANCIAL SHOCKS? THE IMPACT OF THE 2008 STOCK MARKET CRASH
}

\author{
David Dranove \\ Craig Garthwaite \\ Christopher Ody \\ Working Paper 18853 \\ http://www.nber.org/papers/w18853
NATIONAL BUREAU OF ECONOMIC RESEARCH
1050 Massachusetts Avenue
Cambridge, MA 02138
February 2013

The authors would like to thank Jen Brown and Jon Skinner for valuable comments and guidance as well as Katie Johnson from the National Research Corporation and Laura Johnson from the Kaiser Family Foundation for providing useful data. Stephanie Holmes and Matt Schmitt provided valuable research assistance. All errors remain our own. The views expressed herein are those of the authors and do not necessarily reflect the views of the National Bureau of Economic Research.

NBER working papers are circulated for discussion and comment purposes. They have not been peerreviewed or been subject to the review by the NBER Board of Directors that accompanies official NBER publications.

(C) 2013 by David Dranove, Craig Garthwaite, and Christopher Ody. All rights reserved. Short sections of text, not to exceed two paragraphs, may be quoted without explicit permission provided that full credit, including (C) notice, is given to the source. 
How do Hospitals Respond to Negative Financial Shocks? The Impact of the 2008 Stock Market

Crash

David Dranove, Craig Garthwaite, and Christopher Ody

NBER Working Paper No. 18853

February 2013

JEL No. I1,I11,I18,L0,L21

\title{
ABSTRACT
}

The theory of cost-shifting posits that nonprofit hospitals respond to negative financial shocks by raising prices for privately insured patients. We examine how hospitals responded to the sharp reductions in their endowments caused by the 2008 stock market collapse. We find that the average hospital did not engage in cost-shifting, but average hospitals that likely have substantial market power did cost-shift. Investigating further how hospitals responded to the financial setback, we found no evidence of reductions in treatment costs. However, hospitals with large endowment losses delayed purchases of health information technology and curtailed the offering of unprofitable services.

\author{
David Dranove \\ Department of Management and Strategy \\ Kellogg School of Management \\ Northwestern University \\ 2001 Sheridan Road \\ Evanston, IL 60208 \\ d-dranove@kellogg.northwestern.edu \\ Craig Garthwaite \\ Department of Management and Strategy \\ Kellogg School of Management \\ Northwestern University \\ 2001 Sheridan Road \\ Evanston, IL 60208 \\ and NBER \\ c-garthwaite@kellogg.northwestern.edu
}

\author{
Christopher Ody \\ Department of Management and Strategy \\ Kellogg School of Management \\ Northwestern University \\ 2001 Sheridan Road \\ Evanston, IL 60208 \\ c-ody@kellogg.northwestern.edu
}




\section{Introduction}

Firms that experience negative lump sum financial shocks may respond in several ways. They can do nothing, cut expenses, or attempt to raise revenues. Economists usually presume that profit maximizing firms have fully exploited all opportunities to reduce costs or raise revenues, so absent a fundamental rethinking of the firm's strategy, they will have to absorb the negative shock. ${ }^{1}$ In the healthcare sector, however, it is often hypothesized that providers respond to negative financial shocks by raising prices for the privately insured patients, a practice commonly described as "cost shifting."

Proponents of the cost-shifting hypothesis point to data showing that providers lose money treating Medicaid patients and, possibly, Medicare patients, but cover these losses with high private prices. This cross-sectional pricing data demonstrates that hospitals price discriminate but does not provide clear evidence of cost-shifting because it does not tell us whether providers would further increase private prices after experiencing a negative shock—an action Morrisey (1994) describes as “dynamic” cost shifting. If firms do not engage in dynamic cost-shifting, it remains an open empirical question how they respond to financial shocks. Any nonprice responses could have important distributional implications but to date have been largely unexplored.

The theory of cost-shifting is often invoked in health policy discussions. In the 1970s, supporters of all-payer state hospital rate setting programs argued that if states slashed Medicaid payments, hospitals would cost-shift and privately insured patients would bear the burden (Cone and Dranove, 1986). Nearly forty years later, the theory of cost-shifting again found considerable traction during the debate over the Affordable Care Act (ACA), where it was consistently invoked to describe the broad benefits of the proposed reform. ${ }^{2}$ For example, President Barack Obama stated that the "average family pays a thousand dollars in extra premiums to pay for people going to the emergency room who don't have health insurance. So you're already subsidizing other folks; it’s just you're subsidizing the most expensive care”

\footnotetext{
${ }^{1}$ Borenstein and Farrell (2000) posit that profitable firms may suffer from X-inefficiency and will attempt to remove slack if profits fall. Profit shocks can also affect capital investments by firms that utilize internal capital markets. ${ }^{2}$ A good review of the arguments for the ACA, including the federal government argument about cost-shifting and the opponents' response, can be found at http://www.ncsl.org/issues-research/health/us-supreme-court-and-thefederal-health-law.aspx There are literally dozens of blogs and other Internet articles advancing the cost-shifting rationale for the individual mandate. For example, see http://www.americanprogress.org/wpcontent/uploads/issues/2012/02/pdf/individual_mandate.pdf
} 
(Malcolm, 2009). ${ }^{3}$ The practical implication of this statement is that the privately insured already bear the financial externality arising from the large number of uninsured Americans, and therefore they will benefit from policies such as the ACA that are designed to reduce the number of uninsured patients. This externality-based cost shifting argument also served as support for the majority opinion of the United States Supreme Court upholding the constitutionality of ACA (National Federation of Independent Business v. Sebelius).

Despite the strong presumption of cost-shifting underlying the arguments for a variety of major health policy initiatives, few convincing studies exist showing that hospitals actually behave in this manner in the modern healthcare market. Certainly, the oft-cited presence of static price discrimination provides little evidence that hospitals engage in dynamic cost-shifting. By analogy, airlines commonly price discriminate between business and leisure travelers, but we would not conclude that a negative shock resulting from the intensification of competition in the leisure segment would cause airlines to raise business-class airfares. Indeed, if airlines did raise business-class fares in response to this shock, we would wonder why they had previously declined to exert their pricing power. Instead, we expect airlines to respond in other ways, perhaps by accepting lower profits, reducing quality, or making fewer investments.

We will not push this analogy too far, as the institutional features of hospitals may generate different behaviors. One particular and important institutional feature is that most hospitals are non-profit firms that are required to provide a community benefit through activities such as the provision of charity care or the offering of unprofitable services. With institutional features such as this in mind, Dranove (1988) develops a theoretical model in which a utilitymaximizing nonprofit organization that experiences a negative lump sum financial shock engages in dynamic cost-shifting. This theory is best described as "share the gain/share the pain." When hospitals have positive financial shocks, they "share the gain" with their patients by setting prices below profit maximizing levels. When they experience negative shocks, they "share the pain" by increasing prices to recover some of their losses. However, hospitals lacking market power are constrained from increasing prices and must bear the burden in another way.

\footnotetext{
${ }^{3}$ Similar logic is even embedded in the text of the ACA legislation, which states, “... the cost of providing uncompensated care to the uninsured was $\$ 43,000,000,000$ in 2008 . To pay for this cost, health care providers pass on the cost to private insurers, which pass on the cost to families. This cost-shifting increases family premiums by on average over $\$ 1,000$ a year. By significantly reducing the number of the uninsured, the requirement, together with the other provisions of this Act, will lower health insurance premiums” (PPACA, 42 U.S.C. § 18091(2)(F).) Justice Roberts echoed this view in the majority opinion upholding the Act.
} 
While Dranove (1988) found empirical support for his model, numerous changes in the healthcare sector over the last thirty years make it difficult to predict if hospitals still behave in this manner. For example, hospital markets have grown more competitive while many analysts argue that today's nonprofits often behave like "for profits in disguise” (Gaynor and Town, 2012; Ballou and Weisbrod, 2003). Both of these factors limit the ability of hospitals to cost shift following a financial shock. Thus, whether cost-shifting currently exists, as well as the broader concern of who bears the burden of negative hospital financial shocks in the current health care market, remain open and important empirical questions.

The lack of evidence on whether today's hospitals cost-shift is understandable. Testing for this phenomenon requires identifying large exogenous shocks to a provider's finances that do not affect all providers equally and estimating the subsequent changes in private prices. As we discuss in the next section, such plausibly exogenous shocks have proven difficult to find.

Even those studies that have identified and exploited exogenous variation in finances to examine price changes have generally ignored other dimensions hospitals could use to adjust to these shocks. For example, hospitals could decrease operating costs by lowering staffing levels, decrease investments in their physical infrastructure, or curtail the offering of unprofitable services. As a result, these previous studies provide at best an incomplete consideration of hospital behavior and the incidence of financial shocks. These non-price responses are interesting from a distributional and welfare standpoint. If hospitals change quality or service offerings the burden of negative shocks falls on all patients rather than only the privately insured.

We address the gaps in the existing cost-shifting literature by exploiting a recent, large, and plausibly exogenous shock to hospital finances - the stock market collapse of 2008. As a result of this collapse, some hospital endowments suffered large losses while others remained relatively unharmed. Nearly all hospitals rely on income from their investments to help defray operating costs. Thus, the most recent recession created a large and unexpected decrease in hospitals' financial well-being that varied substantially across otherwise similar hospitals, allowing us to empirically identify how hospitals respond to financial shocks.

In order to consider the full range of impacts from hospital financial shocks we examine several categories of hospital responses. First, we focus on two categories of operational responses: pricing changes (i.e., dynamic cost-shifting) and service levels changes (e.g., staffing). Profit-maximizing firms should not be able to increase profits by engaging in dynamic 
cost-shifting and, unless they fundamentally change their business strategy, should not be expected to change their staffing. Among firms that were not previously profit-maximizing, those without market power will find it difficult to cost-shift or alter their variable inputs. Therefore it should not be surprising that we find no evidence that the average hospital costshifts or reduces staffing.

Hospitals with market power that were not setting a profit maximizing price prior to the recession may share the pain of their financial shocks with their customers by raising prices and/or reducing variable inputs. Accordingly, we find evidence of price increases among a small subset of high quality hospitals that likely have some degree of market power. Importantly for policy purposes, these hospitals represent less than 10 percent of all non-profit hospitals and treat less than 20 percent of patients in the United States.

Given that the average hospital did not dynamically cost-shift following a financial shock, we next consider whether these firms changed other aspects of their operations. Specifically, we examine the decision to offer low profit services such as trauma centers or inpatient psychiatric services. Similar to setting lower prices prior to a shock, non-profit hospitals may choose to offer unprofitable services during more profitable time periods as a means of sharing their gains with the community. After the recession, we find that non-profit hospitals suffering larger financial shocks are more likely to eliminate services that are relatively unprofitable. Unlike standard dynamic cost shifting, whose incidence is primarily borne by privately insured patients, the closing of these unprofitable service areas has previously unexplored distributional consequences for individuals without private insurance.

Finally, we examine changes in investments in electronic medical records, a capital intensive technology. Profit-maximizing hospitals that rely on internal capital markets to fund these investments might reduce them following a financial shock. We find evidence of reduced investments in advanced electronic medical records for hospitals suffering large losses from the 2008 recession. Similar to the closing of unprofitable services, delays in implementing these technologies could negatively impact the entire patient population.

\section{Cost Shifting and other Responses to Financial Shocks}

The idea that hospitals would respond to negative financial shocks by increasing private prices dates back at least 30 years. In 1982, the Hospital Association of America described cost- 
shifting as a "hidden tax" paid by insured patients whenever state governments cut Medicaid payments (Health Insurance Association of America, 1982). Hadley and Feder (1985) view costshifting as a survival response by hospitals trying to offset Medicaid cutbacks. The theory of cost-shifting has survived many changes in the healthcare system, notably the growth of managed care, the rise of provider systems, and the spread of for-profit medicine.

The theory of cost-shifting has profound policy implications. Dranove and Cone (1986) argue that when states threatened to slash Medicaid patients, private insurers agreed to participate in all-payer state rate setting plans rather than suffer from cost-shifting. In 1992, the Medicare Prospective Payment Assessment Commission played down the impact of cutbacks in Medicare payments by noting that hospitals could recoup their losses by cost-shifting (ProPAC, 1992). During the recent debate about the PPACA, several industry groups submitted studies claiming that half of all Medicaid and Medicare payment shortfalls were borne by private payers (Frakt, 2011). This theory also served as partial support for the recent Supreme Court decision upholding the constitutionality of the personal mandate component of PPACA. In the majority opinion, Justice Roberts wrote that to recoup the losses from uncompensated care, "hospitals pass on the cost to insurers through higher rates, and insurers, in turn, pass on the cost to policy holders in the form of higher premiums. Congress estimated that the cost of uncompensated care raises family health insurance premiums, on average, by over $\$ 1,000$ per year.” Similarly, Justice Ginsburg wrote in the minority opinion, "[h]ealth-care providers do not absorb these bad debts. Instead, they raise their prices, passing along the cost of uncompensated care to those who do pay reliably: the government and private insurance companies" (National Federation of Independent Business v. Sebelius).

Dranove (1988) offers a formal model of cost-shifting by nonprofit hospitals that we use to motivate our analysis. ${ }^{4}$ In this model, a hospital maximizes some combination of its own profits and its privately insured patients' utility. The hospital faces downward sloping demand from privately insured patients. Thus, when balancing its two objectives, the hospital sets a price below the profit maximizing level. An exogenous lump sum negative financial shock causes the hospital to re-optimize by raising prices so as to partially offset its losses. In this model, a hospital would not distinguish between a financial shock caused by Medicaid cutbacks and a shock from some other source, such as a stock market collapse. We discuss in section 5.2

\footnotetext{
${ }^{4}$ Clement (1997) and Zwanziger et al. (2000) present similar models.
} 
whether there could be practical differences among different types of financial setbacks that would require refinement of Dranove's model.

An important takeaway from Dranove's model is that a hospital observed to cost-shift must not have been previously maximizing profits; had it been profit-maximizing prior to the negative shock, then any increase in private prices would have further reduced profits. Put another way, hospitals will not cost shift unless they have market power and did not fully exploit this power prior to the negative financial shock. Dranove uses this theory to motivate an estimate of the magnitude of cost-shifting by Illinois hospitals in the wake of a sharp reduction in state Medicaid payments, which he treats as a lump sum negative shock. His point estimate suggests that cost-shifting allowed hospitals to make up about half of their lost Medicaid revenue.

As modeled by Dranove (1988), cost-shifting hospitals "share the pain" of negative financial shocks by raising prices to privately insured patients. However, hospitals may also "share the pain" with their patients in other ways, for example by reducing the quality of care or portfolio of service offerings. This is a natural extension of Dranove's model in which nonprofit hospitals, instead of setting a price below the profit maximizing level, offer a level of quality or service provisions above the profit maximizing level. Following a financial shock, hospitals may reduce quality, curtail unprofitable services, or reduce charity care. Few studies to date have investigated whether hospitals pursued these or other strategies.

Morrisey (1994) coins the term "dynamic cost-shifting” to distinguish the causal relationship between financial shocks and private prices posited by Dranove (1988) from the simple fact of price discrimination. This is a critical distinction because Medicare and especially Medicaid have often set prices below the levels paid by private insurers and the gap between government and private prices has varied over time. Many analysts take such price discrimination as prima facie evidence of cost-shifting, and most empirical studies of costshifting are little more than cross-sectional studies demonstrating price discrimination. ${ }^{5}$ This static pricing pattern can be understood through a simple model of price discrimination in which a seller faces two groups of customers, one of which has downward sloping demand and the other has perfectly elastic demand at a preannounced price. Moreover, if marginal cost is

\footnotetext{
${ }^{5}$ See Frakt (2011) for a discussion of this issue. Some studies, such as Gowrisankaran and Town (1997) posit a mechanism whereby cuts in government payments can indirectly trigger increases in private prices, for example by leading to consolidation and enhanced market power. This does not fit the classic description of cost-shifting.
} 
constant or increasing in a simple price discrimination model, a decrease in the government price will lead to a decrease in the private price, which is exactly opposite what is predicted by costshifting. ${ }^{6}$ Thus, it is impossible to infer from the evidence on price-discrimination whether hospitals will engage in dynamic cost-shifting.

A number of empirical studies examine the dynamic relationship between government reimbursements and the price for private patients. For example, Zuckerman (1987) provides evidence that markups by hospitals to private insurers increased between 1980 and 1982, as Medicare reimbursements were cut. At the individual hospital level, however, the correlation is not strong. Zwanziger et al. (2000) examine pricing by California hospitals in the wake of legislation that encouraged price competition in California's health care system. They find evidence that price increases to privately insured patients were strongly correlated with reductions in Medicare payments. Lee et al. (2003) document that revenues from privately insured and Medicare patients tend to be negatively correlated over time and view this as conclusive evidence of dynamic cost-shifting. But this correlation can be obtained from a price discrimination model in which profit maximizing hospitals have increasing marginal costs and experience shocks to private demand, as well as from a model in which changes in Medicare prices are accompanied by entry and other rent seeking behavior, so that total profits remain relatively constant. Without any obvious exogenous shocks to motivate their analysis, these decidedly non-experimental data are hardly dispositive of the cost-shifting theory.

Since Dranove (1988), there have been a handful of studies that exploit exogenous financial shocks. Dranove and White (1998) study how hospitals in California responded to sharp cutbacks in Medicaid payments in the early 1990s, finding hospitals that were highly dependent on Medicaid revenues did not raise private prices. This was a period of rapid growth of managed care, however, which confounds any definitive interpretation of their findings. Other cost-shifting studies examine responses to fluctuations in Medicare payment rates, but most of these present weak tests of cost shifting because changes in Medicare rates tend to be small and transient. Wu (2009) examines a large cut to Medicare rates following the Balanced Budget Act of 1997. As these cuts are correlated with hospital characteristics (such as teaching status) that could independently affect private prices (because of the managed care backlash, for example), it is difficult to interpret the results as causal. In his review of this literature, Frakt

\footnotetext{
${ }^{6}$ See Garthwaite (2012) for an example of this model.
} 
(2011) concludes: “.... as a whole, the evidence does not support the notion that cost shifting is both large and pervasive. Instead, it reveals that cost shifting can occur but may not always do so.”

There are several reasons why we wish to revisit the question of cost-shifting. First the current policy debate about the PPACA demands a fresh look at an issue for which the empirical evidence is far from overwhelming. This is particularly true given that changes in the American health care system over time should result in different patterns of responses by health care providers. $^{7}$ Second, the theory of cost-shifting suggests that hospital pricing policies depend critically on their objectives and their market power; both may have substantially changed since the last wave of studies which focused on hospital pricing in the 1990s. Finally, other than Dranove (1988) and $\mathrm{Wu}$ (2009), the exogenous financial shocks that underlay empirical studies of cost-shifting have been relatively small. We study a recent, dramatic exogenous financial shock - the 2008 collapse on Wall Street. ${ }^{8}$ Many nonprofit hospitals suffered large endowment losses pursuant to the collapse, while others were relatively unscathed. This provides an excellent setting for empirically testing the cost-shifting hypothesis.

Hospitals were not the only nonprofit organizations to suffer endowment losses in 2008. Art museums also suffered large losses and several, including the Art Institute of Chicago, the Brooklyn Art Museum, and the Philadephia Art Museum raised admission fees; the fee in Chicago jumped by 50 percent (Kaufman, 2009). Art museums also cut staff and cancelled costly exhibitions (Henning, 2013). Many universities took big hits to their endowments. While there is no evidence, anecdotal or otherwise, that universities imposed unusually large tuition increases, there is considerable evidence of cost cutting. Harvard University, which suffered a 22 percent endowment decline over a four month period, immediately instituted a hiring freeze and slowed construction projects (Marks and Wu, 2008). Other universities postponed construction, curtailed landscaping and cut back on air conditioning (Hand, 2008). In a more systematic analysis, Brown et al. (2010) found that an endowment shock equal to 10 percent of a university’s budget led to an approximately 3 percent reduction in the number of

\footnotetext{
7 This point was demonstrated in Cutler (1998) which found different responses by hospitals to Medicare cuts in 1980-1985 and 1990-1995. Cutler attributes this difference to the growing role of managed care in the 1990s. ${ }^{8}$ At the mean, the lost profits from the stock market collapse were substantially smaller than the lost profits from the 1997 BBA Medicare cutbacks. The strength of our measure is that there is a great deal of variation in the stock market losses. Wu doesn't provide information on the distribution of revenue losses from BBA. However, she finds a strong negative correlation between cuts in a hospital's Medicare prices and the percent of the hospital's patients covered by Medicare. This strongly reduces the variation across hospitals in the Medicare profit shock.
} 
tenure-track faculty during the year of the shock following by an approximately 6 percent decline in the following year. There were also meaningful declines in support employees. These costcutting responses by museums and universities are consistent with the "share the gain/share the pain” model in which nonprofits respond to financial shocks by reducing quality, where the level of quality prior to the shock exceeded the profit maximizing level. ${ }^{9}$

The responses by art museums and universities suggest that if hospitals do not cost-shift, or do not cost-shift by enough to recover their losses, they may respond to financial shocks in other ways. Hospitals might consider a quality reduction, for example through a reduction in staffing. Hospitals may also curtail unprofitable services or charity care. We also consider one response that is not indicative of the "share the gain/share the pain" hypothesis but does have a potentially large impact on patient welfare. Hospitals that rely on internal capital markets may curtail capital investments (Stein, 1997). During the time period that we study, many hospitals were investing in costly Health Information Technology (HIT) in the form of advanced electronic medical records (EMR). We will test whether hospitals experiencing large stock market price shocks reduced investments in HIT.

\section{Data}

\subsection{Data Sources and Key Variables}

We draw our data from a variety of sources, including Medicare Cost Reports, CMS impact files, the American Hospital Association Annual Survey, the Healthcare Information and Management Systems Society (HIMSS) dataset and some additional sources. We compute our main predictors and dependent variables at the hospital/year level. We supplement these data with a variety of market level controls. Hospital financial data notoriously have outliers, so we censor all time varying variables. ${ }^{10}$ In our main specifications, we restrict ourselves to the years 20032010, so as to begin after the smaller recession of the early 2000 s.

\footnotetext{
${ }^{9}$ Note that in a simple model of quality choice, profit maximizing firms will decrease quality when price-cost margins fall. Several studies show that when government reimbursements fall, hospitals cut back on the quality of care delivered to government-insured patients. For example, see Langa and Sussman (1993). The stock market price shock that we study does not directly affect margins, however, so any accompanying quality reduction would not reflect this simple model.

${ }^{10}$ Specifically, no residuals from regressions with facility and year fixed effects are outside of the $5^{\text {th }}$ and $95^{\text {th }}$ percentiles of residuals.
} 
Our main dependent variable, Price, is constructed from Medicare Cost Reports. Price is revenue per non-Medicare discharge and is identical to a measure constructed by Dafny (2009), except that Dafny's measure is case-mix adjusted, whereas we include case mix as an independent regressor. One shortcoming of Price is that it is an average over different types of patients, including Medicaid and privately insured patients. Thus, changes in Price may confound changes in private prices with changes in Medicaid prices. At a minimum, this introduces noise into our dependent variable and reduces the precision of our estimates. This may also introduce bias if changes in Medicaid reimbursements are correlated with endowment losses. For example, a handful of states cut Medicaid reimbursements after the recession. If our measure of 2008 stock market losses is, for some reason, correlated with state-specific Medicaid cuts or a hospital's Medicaid share, then results using Price would be biased.

We took several steps to deal with this potential bias. First, although several states attempted to cut Medicaid prices, successful injunctions filed by hospitals prevented most of these cuts from taking effect. Nonetheless hospitals may have cost shifted in anticipation of eventual cuts. Therefore, we obtained data from the Kaiser Family Foundation on whether states announced changes in their Medicaid hospital prices in 2008-2010. Our results remain similar when we re-estimate our price analysis excluding the states that announced cuts in any of those years. For some states, Kaiser reports the magnitudes of the announced decreases. We confirmed that our results were further robust to adding back the states for which we could calculate Medicaid price changes using Kaiser’s data to directly control for the Medicaid price changes. Third, we restricted our analysis to hospitals with below average Medicaid market shares in 2007. If our results were confounded by the inclusion of Medicaid pricing, the results for these low-Medicaid hospitals would be different than those for all hospitals. In fact, the results are nearly identical. Finally, we construct an alternative measure of prices, Price2. Price2 results from an analysis that decomposes annual changes in Price into a hospital specific and a statewide component. The latter captures the change in Medicaid reimbursements; the former is Price2. Appendix 1 describes this construction in more detail. Our results using Price2 are similar, albeit less precise, to those using Price and are available upon request.

Our main predictor variable, $\Delta E n d o w m e n t$, is also constructed from Medicare Cost reports. We construct this variable for each system $c$, treating each non-system hospital as its own system. We use system definitions from the 2007 AHA for all years, so that we maintain a 
consistent definition of system membership across our analysis. When computing $\Delta E n d o w m e n t$, we restrict attention to changes in the value of investments and exclude changes in the endowment resulting from operating income or losses. Thus, $\Delta E n d o w m e n t$ represents a true

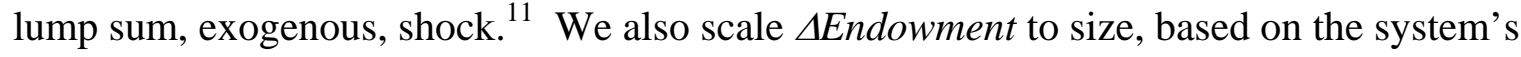
operating costs. We do this because if the theory of dynamic cost shifting is correct, a large hospital suffering a given investment loss would not change price by as much as a small hospital suffering the same magnitude loss. We measure $\Delta$ Endowment for hospital chain $c$ as follows:

$$
\begin{aligned}
& \Delta \text { Endowment }_{c t} \quad=\frac{\text { investment }_{\text {income }} c t}{\text { operat } \widehat{\operatorname{lng}} \operatorname{costs}_{c t}}
\end{aligned}
$$

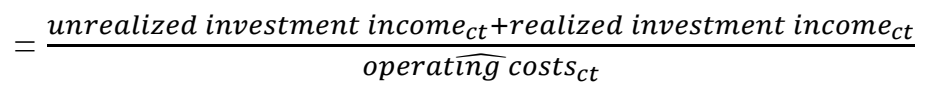

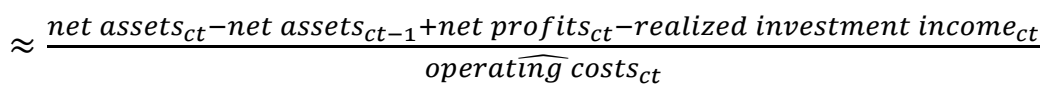

Medicare Cost Reports do not directly report unrealized investment income but it can be inferred as follows. First, we compute the annual change in the hospital's net assets. Net assets can change for three reasons (a) investment income, (b) operating income, and (c), a transfer from a related organization, usually a parent company. We are unable to address (c), so we present separate results for hospitals that do not belong to systems and are therefore unlikely to receive this type of transfer. We also exclude government hospitals and for-profit hospitals because they do not have endowments and therefore the impact of 2008 recession will not come in the form of observable reductions in investment income. For the remaining nonprofit hospitals in our study, we compute investment income by subtracting non-investment related income from the change in net assets. We scale these losses by the predictable component of a system's operating costs. ${ }^{12}$ On average, annual operating costs and net assets are similar in magnitude, but some hospitals have small or even negative net assets, making it inappropriate to scale by a hospital's net assets.

\footnotetext{
${ }^{11}$ Alternatively, one might compute the change in "nonoperating revenue," which consists largely of transfers from the endowment into the operating fund. This is problematic, however, because many hospitals transfer money into the operating fund during the year, realize revenues in excess of costs, and transfer the extra revenues back to the endowment. Hospitals that engage in such accounting practices are not materially different from hospitals that do not transfer endowments. Thus, by measuring changes in operating revenues one creates an artificial distinction based on accounting, rather than economic, differences.

${ }^{12}$ Operating costs are reported directly in the Medicare Cost Reports. dally operatıng costs $s_{l t}$ is a predicted measure of daily operating costs from a model of log daily operating on a full set of hospital and year fixed effects. We use predicted, rather than actual operating costs because actual operating costs may be endogenously affected by endowment returns and would be mechanically endogenous in regressions studying the effect of losses on costs.
} 
Each of the system level variables used to construct $\Delta$ Endowment $_{c t}$ is a sum over the same variable for all hospitals in the system. Because there is more uncertainty in our measure of endowment losses for systems, especially because some endowments may be held by a parent organization that we cannot observe, we present system results separately. ${ }^{13}$ As we discuss further below, the data on systems yield similar conclusions to the non-system hospitals, but are less precisely measured. This is consistent with classical measurement error in our construction of the system endowment losses.

In some analyses below, we examine the ability of a hospital system to withstand profit shocks using their endowments. Specifically, we measure the number of years a hospital system could cover its operating costs solely off of its net assets: Reserves $_{c t}=\frac{\text { net assets }_{c t}}{\text { operating } \operatorname{costs} s_{c t}}$. Hospital system operating costs are very high relative to endowments; even the best endowed hospital systems could only cover one or two years of operating costs with their net assets alone.

\subsection{Additional Dependent Variables}

As discussed in the previous section, the burden of a negative profit shock may be expressed in a number of ways. In addition price changes, we consider the following dependent variables:

\section{Costs per Discharge and other cost measures}

Hospitals suffering a financial setback may reduce the quality of care they provide to patients. There are many ways to measure quality and most are problematic for our purposes, either because they are not systematically available or because they are measured with substantial noise. As suggested by Dranove and White (1998), we assume that the level of services provided to patients, as measured by the cost of care per discharge, is a proxy for quality. We obtain Cost per Discharge from the Medicare Cost Reports. ${ }^{14}$ Cost per Discharge is an "all-in" cost that includes amortized fixed costs. To focus on changes in variable costs, we compute Salaries per Discharge, which equal the total labor costs per discharge for a hospital. From the

\footnotetext{
${ }^{13}$ We exclude two systems from our analysis: Advocate Healthcare (because of data errors) and Kaiser Permanente (because the cost shifting predictions do not cleanly translate to a vertically integrated insurer).

${ }^{14}$ Revenue numbers are reported separately for inpatient and outpatient by revenue center. Costs are not. Therefore, for estimating inpatient costs, we assume that inpatient costs for each cost center are: costs*(inpatient revenues)/(inpatient revenues + outpatient revenues) and then sum over cost centers.
} 
AHA data, we construct additional staffing measures. The variable $R N s$ gives the number of registered nurses and the variable $L P N s$ gives the number of Licensed Practitioner Nurses. ${ }^{15}$

\section{Charitable Services}

Our datasets lack clean or well-populated measures of charity care. For this reason, we focus our analysis on whether the stock market losses affect the offering of relatively unprofitable services. Non-profit hospitals may chose profit maximizing price and quality levels for private patients, but then use the subsequent profits to fund other activities such as the offering of unprofitable services that provide a community benefit. This analysis is guided by Horwitz (2005), which examines the provision of relatively profitable and unprofitable services based on tax status of the hospital. Horwitz finds that for profit hospitals are more likely to offer profitable services and less likely to offer unprofitable services than nonprofit hospitals.

We examine the three unprofitable services for which Horwitz found the strongest relationship between ownership status and the probability of the service being offered: trauma care, emergency psychiatric care, and drug and alcohol treatment. We also consider changes in service offerings for three more profitable services: adult cardiac surgery, extracorporeal shock wave lithotripter, and adult interventional cardiac catheterization. ${ }^{16}$ Each of these is a binary variable taking a value of one if a hospital offers the service and zero if it does not.

\section{Health Information Technology}

In the past two decades, hospitals have made substantial investments in HIT. Two HIT technologies that have been widely adopted since the mid-2000s are computerized provider order entry (CPOE) and physician documentation (PD). Both CPOE and PD may cost upwards of $\$ 10$ million to purchase and install. We obtain data on CPOE and PD adoption from the Healthcare Information and Management Systems Society (HIMSS) Analytics data base. ${ }^{17}$ HIMSS reports

\footnotetext{
${ }^{15}$ The AHA data contains two variables for each staffing measure. In the first, hospitals give "reported FTEs.” In the second, hospitals give "estimated FTEs" which equal full time employees + . 5 * reported part time employees. We use reported FTEs, rather than the estimated number.

${ }^{16}$ Prior to 2004, the AHA asks whether hospitals provided "Open-heart surgery" rather than adult cardiac surgery and a "Cardiac catheterization lab" rather than "adult interventional cardiac catheterization". Therefore, these variables may be slightly different from the ones used by Horwitz. Furthermore, for these two dependent variables we therefore begin our analysis in 2004 rather than 2003.

${ }^{17}$ To reduce the role of coding errors, we do not consider a hospital to have adopted if they report adoption in just one year and re-report that they have not adopted in the next year. If a hospital reports adoption in at least two
} 
different stages of HIT adoption. We define $C P O E$ and $P D$ as dummy variables that equal 1 if the hospital has entered into a contract to install the technology in the year in question or has already begun or completed the adoption process. ${ }^{18}$

\subsection{Control Variables}

Many of our specifications include an array of commonly used control variables that could plausibly impact hospital revenues and pricing decisions, including a measure of local labor market costs computed by Medicare; a measure of the average severity, or the "case mix index," of Medicare patients treated at the hospital (CMI); the percent of discharges from deliveries; lagged county unemployment; and the ratio of medical residents to hospital beds.

Because we draw on a variety of data sets, each with some incomplete data, and because we make some sample restrictions, sample sizes differ from regression to regression. Table 1 illustrates the effects of our sampling restrictions in our Price regressions. Our sample consists of private, nonprofit, acute care hospitals for which we could obtain all relevant variables all of our datasets. CMS does not report CMI for critical access hospitals (CAHs), so they are excluded. It is important to note that our sample is likely weighted towards those hospitals which are most likely to cost shift. For-profit hospitals should exploit their market power at all times, and government hospitals and CAHs are unlikely to have any market power. Therefore, finding no evidence of price changes in this sample makes it highly unlikely that cost-shifting is a broad phenomenon in the modern healthcare market.

Given the concerns about the accuracy of the reported assets in the Medicare cost reports we will present the results based on system status. The final six rows of Table 1 describe that distribution of hospitals in our sample based on their system affiliation.

\section{The 2008 Stock Market Crash and Hospital Endowments}

Before we examine how changes in assets affected hospitals, it is important to demonstrate that hospitals did in fact experience a large financial shock as a result of the 2008 recession. At a minimum, such a shock should be apparent in hospital investment returns. Figure 1a illustrates the percentage return on investments for hospitals based on their system affiliation alongside the

adjacent years, we take the first of these to be the adoption year (i.e. we study time until first adoption, taking reports of unadoption - which we understand never actually happens - as reporting errors).

${ }^{18}$ For further discussion see Dranove et al. (2012). 
returns on the overall S\&P 500. We present all results in this section for non-system hospitals, those in systems with fewer than seven facilities, and those in large systems.

On average, hospitals experienced small negative returns during the 2002 recession and then a far larger decline during the 2008 recession. ${ }^{19}$ Hospital investments appear to be relatively diversified with respect to stock market risk, as evidenced by the dramatically larger movements in the S\&P 500. These average losses mask a large amount of heterogeneity in investment performance across hospitals. For example, the $75^{\text {th }}$ percentile non-system hospital in 2008 experienced a slight investment gain of 0.5 percent while the $25^{\text {th }}$ percentile hospital experienced an investment loss of 7.7 percent. At the extreme, the $5^{\text {th }}$ percentile non-system hospital saw a 2008 investment loss of 22 percent. For comparison, in 2006 the $5^{\text {th }}$ percentile non-system hospital lost only 6.8 percent and the $75^{\text {th }}$ percentile gained 8 percent. This substantial heterogeneity should not be surprising. Hospitals with little exposure to stock market risk should suffer small losses even during a downturn while those with larger exposures should see greater variation in their year to year performance.

Figures 1(b)-1(d) show net assets, operating costs, and reserves (the ratio of net assets to operating costs) for a balanced panel of hospitals for the period 1998-2010 by hospital system status. Across all hospital types there is a small decline in net assets associated with the recession of the early 2000s, and a much larger decline in 2008. Because operating costs climb steadily, reserves fall slightly in the early 2000s and then experience a larger decline in 2008. This drop is greatest for non-system hospitals which experienced an approximately 11 percentage point decline in reserves compared to a 7.5 percent point decline for small system hospitals and a 7.7 percentage point decline for large system hospitals.

We measure the impact of the 2008 recession on hospital finances with the variable $\Delta$ Endowment $_{\mathrm{i} 2008}$, which is the change in the endowment of system $c$ of which hospital $i$ is a member in 2008. To illustrate the impact of the 2008 crash on hospital reserves over time we estimate the following system level equation on hospital data from the years 1998-2010:

\footnotetext{
${ }^{19}$ We do not exploit variation in investment income in years other than 2008 for three reasons. First, in other years we are more concerned that firm investment decisions and pricing decisions are correlated with unobservable factors influencing a hospital's business decisions (i.e. a change in hospital management could lead to changes in the riskiness of a hospital's investment strategy as well as how aggressive the hospital is in negotiations with insurers). Second, there is far less variation in investment performance in other years. Finally, only unexpected changes in wealth should affect pricing and it is unclear how to model firm expectations for investment income in ordinary years.
} 


$$
\text { reserves }_{c t}=\alpha_{c}+\alpha_{t}+\beta_{t}\left(\Delta \text { Endowment }_{c 2008}\right)
$$

where $\alpha_{c}$ is a hospital system fixed effect, $\alpha_{t}$ is a year fixed effect, and $\beta_{t}$ represents a series of coefficients for each year from 1999 to 2010, with 1998 serving as the omitted year. Thus, we ask the relationship between reserves in all years to the investment losses in 2008. Figure 2a plots the estimated $\beta_{\mathrm{t}}$ coefficients and confidence intervals for each year for non-system hospitals. Note that the coefficient has a positive and significant increase in 2008 and 2009, as well as in 2001 and 2002. The latter likely reflects correlated investment strategies, i.e. hospitals pursuing investment strategies subject to stock market risk in 2008 were likely pursuing similar strategies in 2001. We will discuss this correlation in more detail during the analysis of hospital pricing behavior. As would be expected if our measure of losses was capturing the impact of the 2008 recession on hospital finances, $\beta_{2008}-\beta_{2007}$ is approximately equal to 1 . A generally similar pattern is seen in Figure 2b for hospitals that are in systems with fewer than 7 facilities and for Figure 2c for large systems.

The estimates depicted in Figures 2(a) - 2(d) are especially noteworthy because they presage our results about cost-shifting for the average hospital. If hospitals were unable to respond to the investment losses by cost-shifting, and if there was not an immediate recovery of investment losses (i.e. firms with big losses in 2008 did not have commensurately larger gains in 2009), then we would expect $\beta_{\mathrm{t}}=0$ for $\mathrm{t}<=2007$ and $\beta_{\mathrm{t}}=1$ for $\mathrm{t}>=2008$. Indeed, this is approximately what we observe - particularly for non-system hospitals.

Our analysis of the causal impact of financial shocks on hospital behavior rests on the assumption that the losses resulting from the 2008 recession were exogenous. This assumption is primarily supported by the fact that the primary causes of the recession were far removed from the healthcare market. To further examine the plausibility of our identifying assumption, the first panel of Table 2 contains summary statistics based on whether a hospital had above or below average changes in its endowment. Statistics are provided for a variety of the dependent and independent variables described above for the years 2003 to 2006. Overall, the two groups of hospitals are very similar. While the means of many of the variables are statistically different at a p-value of 0.05 they are of similar magnitude and the statistical differences are primarily driven by the precision of the estimates. That being said, hospitals with below average losses had larger staffing levels for both RNs and LPNs. Similarly, these below average loss hospitals were more likely to have psychiatric emergency departments as well as the three relatively profitable 
services described above. Importantly, the two groups of hospitals had price levels that were very similar and statistically indistinguishable.

\section{Results}

We are interested in how hospitals change their behavior across a variety of dimensions in response to financial shocks. In the analysis below, we measure the size of the shock for each hospital through the change in its respective endowment and we begin with a preliminary exploration of the relationship between these losses and the different dependent variables in all years. Specifically, we estimate the following regression on a sample of data from 2003 to 2010:

$$
Y_{i t}=\alpha_{i}+\alpha_{t}+\left[\beta X_{i t}\right]+\lambda_{t}\left(\Delta \text { Endowment }_{i 2008}\right)
$$

where $Y_{\text {it }}$ is the respective dependent variable, $\alpha_{\mathrm{i}}$ are hospital fixed effects, $\alpha_{\mathrm{t}}$ are year fixed effects, $\mathrm{X}_{\mathrm{it}}$ are a variety of time varying hospital level controls that are chosen for the specific dependent variable, $\lambda_{t}$ are a series of year coefficient for the years 2004 to 2010, and $\Delta$ Endowment $_{\mathrm{i} 2008}$ is the change in the endowment from 2007 to 2008 as described above. ${ }^{20,21}$

We assess the results of equation (2) by plotting the $\lambda_{t}$ coefficients and comparing the values before and after 2008. The $\lambda_{\mathrm{t}}$ coefficients indicate the relationship between 2008 hospital endowment losses and the average hospital's behavior. For $t<2008$, we ask whether there is a relationship between the investment strategy of the hospital that led to large 2008 losses and their past behavior with respect to the dependent variables. Similarly, for $t>2008$ we examine whether hospital financial losses in 2008 are systematically related to the dependent variable and therefore provide evidence of cost-shifting.

To obtain a more definitive test of changes in hospital behavior such as cost-shifting, we then aggregate the $\lambda_{t}$ coefficients into a pre- and post- period and estimate the following regression:

$$
Y_{i t}=\alpha_{i}+\alpha_{t}+\left[\beta X_{i t}\right]+\lambda_{\text {post }} * I(\text { year }>2008) *\left(\Delta \text { Endowment }_{i 2008}\right)
$$

\footnotetext{
${ }^{20}$ Note that while in these hospital level regressions, $\Delta E$ ndowment ${ }_{i 2008}$ has a hospital level subscript $i$, this variable is calculated at the system level and independent hospitals are treated as a system with a single unit. Therefore, each hospital in a chain has the same change in investment levels. For this reason, we show results for a sample containing only independent hospitals and for the full sample.

${ }^{21}$ When the dependent variable in a regression is an average (e.g. the price per non-Medicare discharge), we weight each facility in the regression by the facility's average value of the dependent variable's denominator (e.g. the facility’s average non-Medicare discharges). When the dependent is not an average, we leave the regression unweighted.
} 
where I (year > 2008) is an indicator variable for the years after 2008 and all other variables are defined as in equation (2). ${ }^{22}$ For each dependent variable below our estimate of $\lambda_{\text {post }}$ documents the change in behavior following the recession for a hospital based on its endowment losses.

\subsection{Effect of Stock Market Losses on Private Prices}

Our primary question is whether hospitals raise prices for non-Medicare patients after an unexpected financial shock. As a preliminary exploration of this topic we estimate equation (2) with a dependent variable equal to the log non-Medicare price described above. ${ }^{23}$ If hospitals suffering large 2008 investment losses raised prices in response to their losses at a faster rate than did other hospitals, then $\lambda_{t}$ for $t \geq 2008$ should be smaller than $\lambda_{t}$ for $t<2008$. However, if hospitals are unable to raise prices in response to investment losses these coefficients should be similar before and after the recession.

Figure 3a presents estimates of $\lambda_{t}$ by year for non-system hospitals. This figure shows no meaningful change in prices driven by investment losses resulting from the 2008 recession. There is also no pre-trend in the $\lambda_{t}$ coefficients, suggesting that the average hospital's pricing decisions prior to the recession were unrelated to the investment strategy resulting in 2008 investment losses. Figure $3 \mathrm{~b}$ contains a similar analysis for all hospitals in our sample and also reveals no evidence of an impact of the 2008 recession on hospital pricing decisions.

Table 3 contains the estimated coefficients from equation (3) for a dependent variable equal to the log non-Medicare price. Estimates from our preferred specification are presented in columns (3) and (4) for non-system hospitals and the entire sample, respectively. Regardless of the included controls, our results are consistent with the null hypothesis of no cost-shifting.

\subsection{Do These Results Rule Out Cost-Shifting in all Settings?}

These results indicate that the average hospital did not raise prices to recoup losses on its investments. This is inconsistent with the predictions of the Dranove (1988) "share the gain/share the pain" model of dynamic cost-shifting. Thus, we are inclined to conclude that based on existing theory, the average hospital in the contemporary health care system does not

\footnotetext{
${ }^{22}$ For these results we remove 2008 as a transition year. If we include the transition year in the post period, the evidence against cost shifting is even stronger.

${ }^{23}$ We log price both because the variable is highly skewed and because the log specification does a better job of predicting price changes. (This is based on a comparison of price predictions, and is not a simple comparison of $\mathrm{R}^{2}$ across log and linear models.)
} 
cost-shift in response to other financial setbacks, such as reductions in Medicaid or Medicare prices.

However, there may be other behavioral factors that allow hospitals to cost-shift in response to some types of financial shocks and not others. For example, hospitals may view financial shocks from government reimbursement cutbacks as a kind of "focal point" in a dynamic pricing game. Suppose that no hospital in a competitive market would raise prices unilaterally but also that every hospital believes that its rivals will raise prices in response to these cuts. In this case, dynamic cost-shifting becomes a self-fulfilling prophecy that follows changes in government reimbursement systems. Another possibility is that non-profit payers and non-profit hospitals view the increased prices following a government price cut as a portion of their respective community benefit responsibilities and this changes the dynamics of their bilateral negotiations.

The need to expand the existing cost shifting theories to explain our results makes it clear that to the degree cost shifting is present in the modern healthcare market, it is a limited phenomenon related to a subset of all financial shocks. This is important for considering the impacts of important policy changes such as the ACA. The primary cost-shifting argument supporting the ACA is not the result of a government reimbursement change but is instead the result of a potential reduction in uncompensated care. While our results are not a direct test of this phenomenon, they clearly demonstrate that support for the ACA based on uncompensated care related cost shifting must rely on more nuanced theories than currently exist.

\subsection{Do a Subset of Hospitals Cost-Shift?}

While there may be a need for new theories of cost shifting for specific types of financial shocks, the lack of a response for the average hospital is also consistent with existing cost-shifting theories. Recall from Dranove (1988) that hospitals engaging in dynamic cost-shifting must both possess pricing power and, prior to the financial shock, they must have not fully exploited this power. $^{24}$ In our full sample it is likely that the majority of hospitals fail on at least one of these

\footnotetext{
${ }^{24}$ We focus on whether there is heterogeneity in the response to cost shifting that is consistent with the Dranove (1988) model. Other models might suggest other subsets of hospitals within which to test for cost shifting. For example, a loose interpretation of the theory of cost shifting might suggest that hospitals will not raise prices unless they "really have to." While translating this hypothesis into an empirical test is imprecise at best, we made two attempts. First, we split the sample by the size of the 2007 endowment - hospitals with smaller initial endowment might "really have to" increase profits. Second, we split hospitals based on their 2007 operating margins from non-
} 
two dimensions. While it is not possible to determine ex ante whether hospitals are profit maximizing, we are able to identify hospitals that plausibly have market power. ${ }^{25}$ Finding evidence of price changes among hospitals with market power would suggest that the lack of an effect for the remaining hospitals is not solely a result of endowment losses being viewed as distinct from other financial shocks.

Since there is no obvious method of measuring the relative market power of hospitals in a nationwide sample, we pursue two ad hoc approaches. First, we ask whether a hospital was either nationally ranked in the US News and World Report annual hospital rankings or whether the hospital serves as the main teaching affiliate of a medical school (hereafter referred to as high quality hospitals). It is reasonable to assume that high quality hospitals have more pricing power than the average hospital. Figure 3c contains the estimated coefficients from two specifications of equation (2) for non-system hospitals based on this proxy measure of market power. The solid line depicts the $\beta_{\mathrm{t}}$ coefficients for the high quality hospitals sample while the dashed line represents the coefficients for the remaining hospitals.

There is a definitive pre-trend from 2003 up to 2007 where high quality hospitals with larger 2008 endowment losses decreased their prices compared to hospitals with smaller endowment losses. This pre-trend could result from correlation in the investment returns from strategies resulting in greater endowment losses in 2008. Under a "share the gain” model, hospitals would return some portion of these investment returns in earlier periods to privately insured patients in the form of lower prices. We find evidence of this potential channel in an unreported analysis of the investment returns of the sample of high quality hospitals. Specifically, a hospital which had endowment losses of 1 percent of operating costs in 2008 had previously earned an extra 0.27 percent of operating costs in investment returns from 2003 up to 2007-the years of the pre-trend. Following 2008 there is a clear trend break where high quality hospitals suffering large investment losses discontinued their previous pattern of decreasing

investment activities. Hospitals with worse non-investment performance might be more reliant on investment activities to cover their costs, and therefore might "really have to" increase profits. We did not uncover any important heterogeneity in response based upon these hospital characteristics. Results from these specifications are available upon request..

${ }^{25}$ Conventional wisdom says that government and religious hospitals behave more like non-profits than do other non-profit hospitals. Government facilities are excluded from our analysis. In unreported results, we failed to find any break from pricing trends from the stock market crash among religious non-profits. The religious non-profits have both smaller average losses and less dispersion in their losses (for example, there is a 90-10 difference in $\Delta$ Endowment $_{i 2008}$ of 0.18 in for the non-religious nonprofits vs. 0.12 for religious non-profits). 
prices. This would be consistent with a "share the pain" model where these hospitals raise prices in response to a financial shock. Therefore, both the pre-trend and the post-2008 deviation from this trend provide evidence in support of the "share the gain/share the pain" model of hospital pricing behavior in this high quality sub sample.

In order to estimate the statistical significance of this trend break we re-estimated a specification of equation (3) including an interaction between $\Delta E n d o w m e n t_{\text {i2008 }}$ and a linear time trend. In this specification, a statistically significant and negative $\lambda_{\text {post }}$ coefficient would serve as evidence that hospitals suffering large financial shocks broke from the positive pre-trend in pricing behavior. This would result in prices that were higher following 2008 than would have been expected in the absence of the investment losses. Columns (5) and (6) of Table 4 contains the estimates from this specification for non-system high quality hospitals and the full sample of high quality hospitals, respectively. These estimates show a statistically significant (pvalue $<0.05)$ change in pricing behavior for these hospitals. This negative coefficient means that high quality hospitals suffering larger investment losses in 2008 exhibited some cost shifting behavior. For comparisons sake, a similar pre-trend analysis for all hospitals is contained in columns (5) and (6) of Table 3. These estimates are small and statistically insignificant.

The dashed lined in Figure 3c depicts the estimates for the remaining hospitals not included in these high quality rankings. These facilities display neither a pre-trend nor evidence of cost-shifting. An unreported analysis of these hospitals also demonstrated correlation between 2008 investment losses and returns in earlier years. However, if these hospitals truly do not possess market power we would not expect that they "shared the gain” of these earlier returns given that they cannot subsequently share the pain through higher prices when they suffer financial shocks. Therefore, if our ad hoc measure of market power is accurate we would not expect these hospitals to exhibit a positive pre-trend in Figure 3c. Importantly, the hospitals represented by the dashed line comprise approximately 94 percent of the facilities and treat 82 percent of the patients in our sample, demonstrating that the vast majority of patients did not face higher prices as a result of the 2008 financial shock.

One concern with the above results is that high quality hospitals with large investment losses were fundamentally different from similar quality hospitals with smaller losses and our estimates are just picking up this difference. To examine this possibility, the second panel of Table 2 contains summary statistics for high quality hospitals based on the size of the 
endowment losses. These hospitals are all very similar across a wide variety of characteristics suggesting that the changes in pricing behavior are not the results of systematic differences in this group of hospitals based on investment returns.

Another concern about our high quality hospitals results is that our proxy for market power may be too narrow and therefore our control group contains a mix of hospitals with and without market power. To address this concern we developed a broader measure derived from a national survey of consumer perceptions of hospital quality. These data, the Market Insights survey by the National Research Corporation (National Research), are an annual survey of approximately 270,000 respondents in 250 geographic markets. All respondents are over the age of 18 and the sample is weighted according to age, population density, income, race, presence of children in the home and marital status. National Research asks consumers about the characteristics of hospitals in their area and we treat the hospitals that respondents identify as having the "Best Overall Quality" as the facility that they prefer. Importantly, this question focuses on overall quality and not which hospital patients actually attend and thus abstracts away from insurance networks and prices. We use this measure of patient preferences to construct a pseudo-“patient flows” hospital HHI. More specifically, we calculate a zip code HHI and then calculate a hospital HHI as a patient weighted average of the zip code HHIs. ${ }^{26}$ Despite this measure suffering from some degree of bias and measurement error (Kessler and McClellan, 2000), it provides an approximate measure of hospitals that face more versus less competition. ${ }^{27}$

We group hospitals by terciles of this measure of consumer preferences. Figures 4a and $4 \mathrm{~b}$ present the estimates from a specification of equation (2) for non-system hospitals in the first and third terciles of this proxy measure for hospital market power. The pricing behavior of these groups of hospitals is similar and does not provide any evidence of cost-shifting. Figures 4c and 4d provide similar estimates for all hospitals in the first and third terciles and similarly portray no evidence of cost shifting among the hospitals in the top tercile of our HHI measure.

\footnotetext{
${ }^{26}$ We match the National Research data and the Cost Reports on facility name, hospital zip code and the zip codes of patients choosing the hospital. This process works imperfectly. We use all National Research facilities to calculate HHIs, using system affiliation in calculating HHIs when we successfully match across the datasets. We successfully match $87 \%$ of hospitals in our final sample to the National Research data and restrict the analysis to this subset.

${ }^{27}$ We also constructed private patient HHIs using Dartmouth Atlas Health Referral Regions (HRR) as our unit of geography. It is important to note that given the size of this geographic error, this measure of market power suffers from a great deal of measurement error. We found no connection between pricing and stock market losses for hospitals in less competitive markets, or for the hospitals with larger shares of private patients within an HRR.
} 
Our estimates using two different proxy measures of market power demonstrate that only a small subset of hospitals cost shift after their investment losses. These hospitals are exceptionally high quality and this pricing behavior may be a result of their market power. Importantly for policy considerations, these high quality hospitals represent less than 10 percent of United States hospitals.

\subsection{Effect of Stock Market Losses on Operating Costs}

In this section, we study whether hospitals responded to endowment losses by cutting costs. Similar to our analysis of price, we run two sets of regressions for each of our cost measures. We concentrate on four cost and staffing related outcomes: $\ln ($ Cost per Discharge), $\ln ($ Salaries per Discharge $), \ln (1+R N s)$ and $\ln (1+L P N s) .{ }^{28}$ We plot the results from the pre-trend analysis using our preferred set of controls in Figures 5 and $6 .^{29}$ Estimates from the pooled posttreatment specification are presented in Table 5.

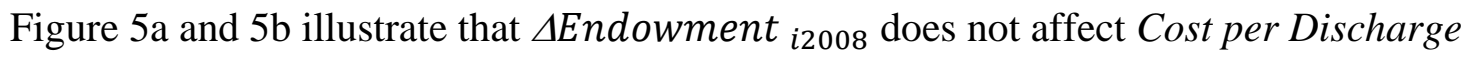
trends in both the pre or post period for non-system hospitals and the full sample respectively. Using column (1) of Table 5 as our preferred specification, we can rule out cost decreases for non-system hospitals of greater than 0.15 percent in response to an endowment loss equal to 1 percent of operating costs.

Figure $5 c$ and $5 d$ plots $\lambda_{t}$ by year from our preferred specification of the effect of $\Delta$ Endowment $_{i 2008}$ on logged salaries per discharge. Again, there is no pre-trend and no evidence of a change in labor costs after the stock market crash.

There is also little relationship between the number of employees and investment losses. Figure $6 \mathrm{a}$ and $6 \mathrm{~b}$ and the results contained in the last panel of Table 5 examine the effect of the crash on the number of full time equivalent registered nurses (RNs) at a hospital. Figure 6a and $6 \mathrm{~b}$ illustrate that there is no pre-trend in the effect of endowment losses on RN staffing, and that there is no effect after the losses.

\footnotetext{
${ }^{28}$ The controls are similar, but not identical across specifications. In particular, we use a measure of volume from the AHA (Cost Reports) data as a control when our dependent variable is from the AHA (Cost Reports) data. The variable "adjusted" discharges is defined in the AHA data as Inpatient Days + (Inpatient Days * (Outpatient Revenue/Inpatient Revenue)). Our results are not sensitive to this decision and the estimates from alternate specifications are available upon request.

${ }^{29}$ These preferred controls correspond to the controls in columns (1) and (2) of Table 5 for the cost measures. The preferred controls are in columns (1) and (2) of Table 6 for the staffing measures. The results are not sensitive to this choice.
} 
Figures 6c and 6d illustrate that there is no pre-trend in the effect of endowment losses on the number of licensed practical nurses (LPNs), but suggests that non-system hospitals with larger endowment losses decreased the number of LPNs that they hired in the post period. Taking column (5) of Table 5 as our point estimate, a hospital with endowment losses equal to 1 percent of operating costs decreased LPNs by a statistically significant 0.4 percent (p-value < 0.10). It is important to note that, despite their statistical significance, these changes in LPN staffing are not economically meaningful in terms of the ability of a hospital to recoup large investment losses. Table 2 illustrates that over 80 percent of nurses in our sample are RNs.

Overall, there is little economically meaningful adjustment of patient costs following a financial shock. As a caveat, these costs results are less generalizable to other types of profit shocks such as Medicare and Medicaid price cuts than our price results. Profit maximizing hospitals would not respond to wealth shocks with "cost shifting” or "cost cutting," but could be expected to respond to price changes (i.e., Medicare and Medicaid price cuts) by decreasing per patient costs. This is because when margins fall, profit maximizers have incentives to reduce costs, which normally entails reductions in quality.

\subsection{Effect of Stock Market Losses on Hospital Service Offerings}

In this section, we examine whether hospitals respond to financial shocks by changing the mix of services they offer, with a focus on changes to relatively unprofitable services. We begin by estimating equations (2) and (3) using the full set of control variables. Next, we reestimate these equations without two control variables, CMI and \% Deliveries, which are likely to be endogenously determined by the mix of services. The results across these specifications are remarkably similar and therefore we report the specifications without the potentially endogenous variables. Since all of the variables in these specifications come from only AHA data, we are able to use data through 2011. Given that it may take longer for hospitals to adjust service offerings than to adjust prices or costs, estimates from this longer sample present a more accurate picture of hospital responses than data only through $2010 .^{30}$

Figure 8a presents the estimates from equation (2) for non-system hospital trauma centers. There is little evidence of a pre-trend, but beginning in 2008 there is a notable change in

\footnotetext{
${ }^{30}$ Estimates from the sample containing the years up to 2010 are generally similar to those from 2011. For example, the coefficient (standard error) on $\lambda_{\text {post }}$ for a sample to 2010 for trauma centers, psychiatric facilities, and alcohol and drug treatment are $0.214(0.138), 0.217$ (0.145), and $0.251(0.130)$, respectively.
} 
the pattern of the estimates suggesting that hospitals suffering larger financial losses in 2008 were relatively less likely to have a trauma center following the recession. The statistically significant (p-value $<0.10$ ) estimate for non-system hospitals in column (1) of Table 6 is 0.257 and suggests that a hospital which had a one standard deviation (0.07) greater endowment loss was 1.8 percentage points less likely to have a trauma center in the post period.

Generally similar results are seen in Figure 8b and column (2) of the first panel in Table 6. However, for the full sample of hospitals there is a pre-trend which shows that hospitals with larger 2008 losses were relatively more likely to have trauma centers prior to the recession. This again serves as further evidence of the "share the gain" model. Hospitals with larger losses in 2008 also larger gains earlier in our sample and this pre-trend is consistent with these hospitals channeling some of these gains into societally valuable but unprofitable services. Similar to the high quality hospital price analysis, the impact of the 2008 financial shock on service offerings in the presence of this pre-trend can be estimated through a specification of equation (3) that includes an interaction between the endowment losses variables and a linear time trend. The estimated coefficient (standard error) on $\lambda_{\text {post }}$ from this specification is 0.263 (0.162) with a pvalue 0.104 . The estimate from this specification for non-system hospitals is a statistically significant (p-value < 0.10) $0.369(0.210)$.

Figure 8(b)-8(c) and columns (1) and (5) of the first panel of Table 6 present estimates for the two remaining unprofitable service types for non-system hospitals: psychiatric emergency services and drug and alcohol outpatient services. For both of these service types, it is impossible to definitively rule out or rule in pre-trends: both have point estimates for $\lambda_{2007}$ which are within 0.01 of the 2003 level. Hospitals with larger endowment losses were relatively less likely to offer these services after 2008. For drug and alcohol outpatient services, this result is statistically significant at a p-value of 0.10 . For psychiatric emergency services, the estimates are suggestive but statistically insignificant at conventional levels. We test whether the post period values are jointly statistically significant across the three service types, and obtain a pvalue of 0.0605 . A similar test for specifications containing a linear time trend has a p-value of 0.0550 .

These estimates suggest that the average hospital suffering a large financial shock is more likely to eliminate some unprofitable service offerings than a similar hospital suffering a smaller shock. An open question is whether hospitals will also begin offering more profitable services 
following investment losses. Figures 7(d) and 8(d) contain the estimates from a specification of equation (2) for adult cardiac surgery centers for non-system facilities and all hospitals, respectively. These graphs show neither a pre-trend nor a reaction to the 2008 financial shock. Panel B of Table 6 contains the estimates from equation (3) for three of the relatively profitable services identified in Horwitz (2005). Neither the non-system hospitals nor the full sample increased their provision of relatively profitable services in response to the 2008 financial shock.

\subsection{Effect of Stock Market losses on Electronic Medical Records Adoption}

Hospitals that use internal capital markets to fund capital expenditures might decrease these investments following a financial shock. We now turn our attention to the decision by a hospital to make investments in two types of advanced electronic medical records (EMR): computerized provider order entry (CPOE) and physician documentation (PD). HIMSS data report CPOE and PD adoption beginning in 2003 and 2005, respectively. We restrict our sample to hospitals which had not adopted as of the first year data were collected. ${ }^{31}$ As a result of a number of factors, including but not limited to explicit federal policy incentives, adoption has progressed at a rapid pace and is nearing saturation by the end of our sample period.

Given the nature of the question, specifically whether hospitals choose to adopt a particular technology, we document basic adoption patterns by first running a simple Cox proportional hazard model. The probability that a hospital $i$ that has not adopted by $t-1$ adopts by time $t$ is given by:

$$
h(t)=h_{0}(t) e^{\lambda_{t}\left(\Delta E n \text { dowment }_{i 2008}\right)}
$$

The function $h_{0}(t)$ is not estimated. Instead, the Cox model only identifies off of variation within observations with the same $t$ and therefore the same $h_{0}(t)$. Notably, we include no control variables, so $e^{\lambda_{t}}$ gives the only the effect of $\Delta E n$ dowment $_{i 2008}$ on the hazard function, i.e. these results document the adoption patterns in all time periods for hospital implementing investment strategies that result in large 2008 investment losses. Table 7 reports $e^{\lambda_{t}}$ from these regressions. Columns (1) and (3) are restricted to the non-system facilities, whereas (2) and (4) include all facilities. Overall, the estimated coefficients are generally less than one, indicating that facilities with larger endowment losses were more likely to adopt advanced EMR. However,

\footnotetext{
${ }^{31}$ About $19 \%$ of hospitals for which we have our measure of $\Delta$ endowments adopted CPOE by 2003 . About $27 \%$ of hospitals which we have $\Delta$ endowments adopted PD by 2005. Our results are very similar if we include these hospitals and set adoption to that first year.
} 
the point estimates from 2008 are notably larger (particularly in the case of CPOE) indicating that these hospitals were less likely to adopt during this year. This is consistent with reports that hospitals put off EMR investment because of the stock market crash (HIMSS, 2011).

While hospitals experiencing large 2008 investment losses might have generally been more likely to adopt advanced EMR, we are interested in the causal impact of the financial shock from the 2008 recession on these investment decisions. Following our previous analyses, we next estimate a model that both controls for the effect of $\Delta E n d o w m e n t_{i 2008}$ on the baseline adoption hazard and allows for the effect of $\Delta$ Endowment $_{i 2008}$ to differ in the post period by estimating the following specification:

$h(t)=h_{0}(t) e^{\left[X_{i t} \beta\right]+\lambda\left(\Delta E n \text { dowment }_{i 2008}\right)+\lambda_{2008} * I\left(\text { year }^{2} 2008\right) *\left(\Delta \text { Endowment }_{i 2008}\right)+\lambda_{\text {post }} * I(\text { year }>2008) *\left(\Delta E n d o w m e n t_{i 2008)}\right.}$

where $\lambda$ gives the average effect of $\Delta$ Endowment $_{i 2008}$ on adoption, $\lambda_{2008}$ gives the additional effect on adoption in 2008, $\lambda_{\text {post }}$ gives the additional effect on adoption for the years after 2008. We also add a number of controls $\left(X_{i t}\right): A R R A$ is an estimate of the benefits from the American Recovery and Reinvestment Act of 2009 on adoption ${ }^{32}$ and ACGME is an indicator variable for whether a hospital is every listed as accredited for Graduate Medical Education in the AHA data. For each of these variables we include the variable's average effect in the pre period, its additional effect in 2008 and its additional effect in the year after 2008. For the analysis which includes systems, we also include interactions between whether a facility is in a system and the pre period, 2008, and post-2008 variables.

The results, presented in Table 8, suggest that the endowment losses had an immediate negative effect on adoption of CPOE. To facilitate interpretation t-statistics are reported in parentheses. The coefficient of less than one on $e^{\lambda}$ implies that hospitals with large 2008 losses were more likely to adopt in the pre period. Importantly, the large coefficient on $e^{\lambda_{2008}}$ means that, after controlling for the baseline probability of adopting, hospitals with larger investment losses were less likely to adopt CPOE in 2008 compared to hospitals with smaller investment

\footnotetext{
32 The American Recovery and Reinvestment Act gave certain hospitals financial incentives to adopt advanced EMR. We define ARRA to be a standardized variable giving a hospital's 2011 Medicare incentive payment for meaningful adoption divided by the hospital's average operating costs. Under the ARRA, hospitals with 1,15023,000 discharges per year and a high Medicare share have stronger incentives to adopt. More specifically, a hospital's incentive payments are:

$$
\{2,000,000+[\text { discharges } \in(1150,23000)] *(\text { discharges }-1150) * 200
$$$$
+[\text { discharges }>23000] *(21851 * 200)\} *(\% \text { Medicare })
$$

We calculate this incentive using averaged hospital characteristics. Then we divide the incentive payments by a hospital's average operating costs and then standardize the measure.
} 
losses. In this sample, $\Delta$ Endowment $_{i 2008}$ has a standard deviation of 0.07 . The coefficient of 290.6 in column (3) of Table 8 implies that a non-system hospital with losses one standard deviation below the mean would have an adoption probability that was 67 percent $\left(e^{-.07 * \ln (290.6)}\right)$ of the adoption probability of a hospital at the mean in 2008 when compared with in the pre period. This result is only marginally significant (p-value $<0.10$ ), which is unsurprising as this exercise imposes relatively weak assumptions and therefore pushes the data hard.

The other coefficients in the CPOE regressions are also as would be expected. In particular, hospitals receiving large financial incentives to adopt under ARRA were less likely to adopt prior to the passage of the legislation and more likely to adopt afterwards. The effects are substantially muted in the whole sample. The adoption decisions of facilities within systems are highly (but not perfectly) correlated, meaning the decisions of a few large systems can have a large effect on the full results. Furthermore, differences among the decisions of systems are likely to be important but difficult to control for in the data. The second panel in Table 8 illustrates no statistically significant effect of endowment losses on PD, although the coefficients move in a similar direction to the CPOE estimates. The controls, such as ARRA, also appear less successful in explaining the pattern of PD adoption.

While Cox models are in some respects more flexible than fully parametric hazard models, the estimates require careful interpretation. Note that if a hospital has observable characteristics that make adoption more likely but has not adopted early, the proportional hazards model will continue to predict the hospital to be a likely adopter. Therefore, if the hospital has not adopted because of unobserved characteristics that make adoption unattractive, our estimates may be biased. We document that hospitals with large 2008 losses were more likely to be early adopters of advanced EMR. If they had not adopted by 2008, that may be explained by unobservable characteristics. It is important to note that if our results were driven by such a survivor bias, then we would expect a smooth change in how $\Delta E$ Endowment ${ }_{i 2008}$ affects adoption over time. The change we observe is stark, suggesting that they are not simply the result of a survivor bias. Still, to further alleviate concerns about potential bias from our modeling choice, we illustrate that our results are robust to a fully parametric specification. We assume a hazard function of:

$$
\left.h(t)=h_{0}(t) v e^{\left[X_{i t} \beta\right]+\lambda_{t}(\Delta E n d o w m e n t}{ }_{i 2008}\right)
$$


where $v$ is a randomly distributed variable drawn from the inverse normal distribution. In this specification, hospitals which ought to have adopted (based on observables) but haven't are less likely to adopt in the future because they likely have unobservables that make adoption unattractive. This model is more flexible than the Cox because it weakens the assumption that current adoption probabilities cannot depend upon past adoption probabilities. Without specifying the hazard function, this model is no longer identified. Therefore, we impose the restriction that the hazard function, $h_{0}(t)$, is a Weibull distribution.

Results from this model are presented in Table 9. Column 5 of the CPOE results implies that a non-system hospital with losses one standard deviation below the mean would have an adoption probability that was 62 percent $\left(e^{-0.07 * \ln (903.9)}\right)$ of the adoption probability of a hospital at the mean in 2008 when compared with in the pre-period. This is generally similar in magnitude, but more precise, to our results in Table 8. Overall the estimates in Table 9 demonstrate that our finding that non-system hospitals decreased capital expenditures in response to the 2008 financial shock are not driven by the specification choice in equation (5).

\section{Conclusion}

The 2008 recession led to large endowment losses for non-profit hospitals. This exogenous variation in wealth provides a unique opportunity to examine hospital responses to lump sum financial shocks. It is often assumed that hospitals absorb the impact from financial shocks from policy changes such as Medicare or Medicaid reimbursement reductions by raising prices on privately insured patients. If hospitals do raise prices, the incidence of these policy changes falls primarily on privately insured patients and not the program's direct beneficiaries. However, we find no evidence that the average hospital raises prices in response to losses in endowments.

Existing theories of cost shifting suggest that the failure to observe a price increase could indicate either (a) the average hospital lacks market power, or (b) the average hospital previously set prices at profit maximizing levels and therefore should not raise prices following a financial shock. Therefore, we examine a smaller sample of high quality hospitals that likely have some market power over private insurers. We find that these hospitals raised their prices compared to what they would have been in the absence of the financial shock. Given that these hospitals 
represent only less than 10 percent of all facilities and treat less 20 percent of patients in our sample, it is unclear how important their response is for the average privately insured patient. Hospitals may not cost shift in response to negative financial shocks but they may respond in other ways. We find no evidence that hospitals cut staffing, which stands in contrast with how universities responded to the financial crisis. We do find that hospitals decreased large capital expenditures on advanced medical records and curtailed the offering of unprofitable services such as trauma centers and alcohol and drug treatment facilities. These reactions provide valuable information for evaluating the incidence of policies generating financial shocks for hospitals. Rather than simply impacting the prices paid by privately insured patients, these policies can result in broad changes in the quality and availability of health services for all patients. For example, the closing of trauma centers can limit access to critical health services for vulnerable and disadvantaged populations. Hsia and Chen (2011) document that the closures of trauma centers between 2001 and 2007 have already increased the travel time to such a facility for communities with high numbers of uninsured, poor, and African American residents. Future closures of trauma centers or other unprofitable services from financial shocks to hospitals could exacerbate these disparities. By documenting these non-price responses, we are among the first studies to explore the variety of alternate avenues by which hospitals adjust their operations to react to financial shocks. 


\section{Table 1}

Impact of Sample Restrictions on Sample Size

\begin{tabular}{|c|c|c|c|c|c|c|c|c|}
\hline & 2003 & 2004 & 2005 & 2006 & 2007 & 2008 & 2009 & 2010 \\
\hline Initial observations in HCRIS data & 6,223 & 6,221 & 6,218 & 6,178 & 6,199 & 6,176 & 6,175 & 5,906 \\
\hline
\end{tabular}

Number of observations in HCRIS data after dropping observations

with:

Duplicates, missing addresses, Long-Term Care, psych and rehabilitation hospitals, Outlying territory hospitals.

$\begin{array}{llllllll}4,931 & 4,962 & 4,947 & 4,892 & 4,884 & 4,857 & 4,834 & 4,635 \\ 4,856 & 4,895 & 4,895 & 4,848 & 4,832 & 4,801 & 4,789 & 4,587 \\ 2,830 & 2,828 & 2,814 & 2,769 & 2,769 & 2,758 & 2,740 & 2,610 \\ 2,320 & 2,218 & 2,095 & 2,018 & 2,014 & 1,998 & 1,970 & 1,873 \\ 1,907 & 1,924 & 1,932 & 1,952 & 1,980 & 1,988 & 1,942 & 1,829 \\ 1,776 & 1,803 & 1,816 & 1,822 & 1,857 & 1,823 & 1,793 & 1,702\end{array}$

Remaining observations by 2007 system size:

\author{
Non-system \\ Under seven hospitals
}

Seven or more hospitals

Remaining Systems x years by 2007 system size:

Non-system

Under seven hospitals

Seven or more hospitals

$\begin{array}{llllllll}801 & 812 & 810 & 811 & 822 & 819 & 800 & 760 \\ 463 & 476 & 478 & 473 & 492 & 479 & 478 & 452 \\ 512 & 515 & 528 & 538 & 543 & 525 & 515 & 490\end{array}$

\begin{tabular}{cccccccc}
815 & 821 & 827 & 832 & 840 & 842 & 819 & 776 \\
167 & 167 & 167 & 166 & 167 & 168 & 167 & 161 \\
41 & 41 & 41 & 41 & 41 & 41 & 41 & 41 \\
\hline
\end{tabular}




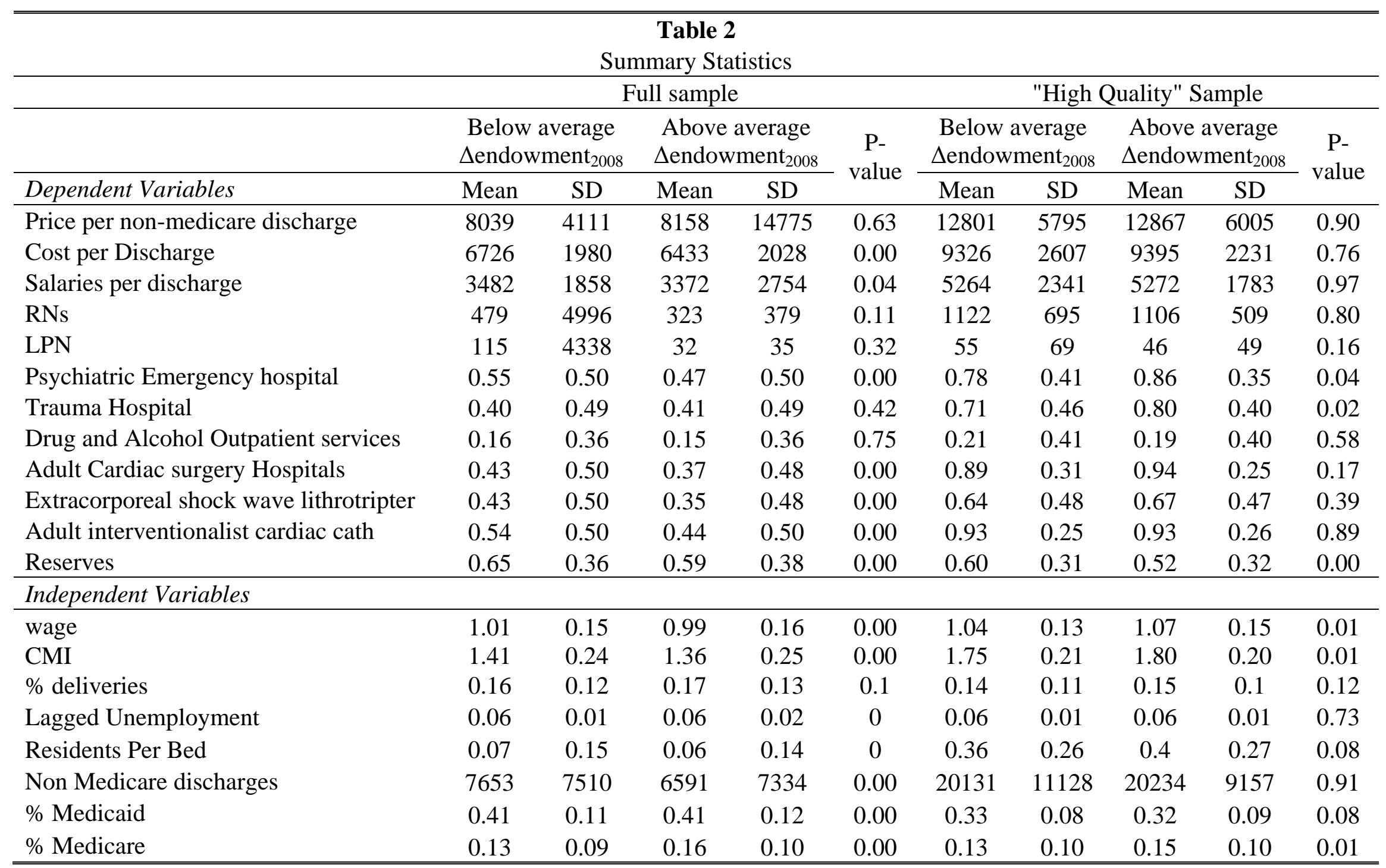

Unit of observation is the hospital by year for the years 2003 to 2006. 


\begin{tabular}{|c|c|c|c|c|c|c|}
\hline \multicolumn{7}{|c|}{$\begin{array}{c}\text { Table } 3 \\
\text { OLS Estimates of the Impact of Financial Shocks on Log Prices }\end{array}$} \\
\hline & $(1)$ & $(2)$ & $(3)$ & (4) & (5) & (6) \\
\hline investment returns $_{\mathrm{i} 2008} *($ year>2008) & $\begin{array}{l}-0.0961 \\
(0.114)\end{array}$ & $\begin{array}{l}-0.0762 \\
(0.0886)\end{array}$ & $\begin{array}{l}-0.135 \\
(0.119)\end{array}$ & $\begin{array}{l}-0.0939 \\
(0.0894)\end{array}$ & $\begin{array}{l}0.0165 \\
(0.143)\end{array}$ & $\begin{array}{l}-0.0466 \\
(0.118)\end{array}$ \\
\hline $\ln$ (wage) & & & $\begin{array}{l}0.297 * * \\
(0.138)\end{array}$ & $\begin{array}{l}0.368 * * \\
(0.112)\end{array}$ & $\begin{array}{l}0.292 * * \\
(0.137)\end{array}$ & $\begin{array}{l}0.367 * * \\
(0.112)\end{array}$ \\
\hline $\ln (\mathrm{CMI})$ & & & $\begin{array}{l}0.249 * * \\
(0.103)\end{array}$ & $\begin{array}{l}0.388 * * * \\
(0.0676)\end{array}$ & $\begin{array}{l}0.254^{* *} \\
(0.103)\end{array}$ & $\begin{array}{l}0.389 * * * \\
(0.0678)\end{array}$ \\
\hline$\%$ deliveries & & & $\begin{array}{c}0.751^{* * *} \\
(0.122)\end{array}$ & $\begin{array}{c}0.649 * * * \\
(0.0867)\end{array}$ & $\begin{array}{c}0.751^{* * *} \\
(0.123)\end{array}$ & $\begin{array}{c}0.650 * * * \\
(0.0868)\end{array}$ \\
\hline Lagged Unemployment & & & $\begin{array}{c}0.740 \\
(0.623)\end{array}$ & $\begin{array}{c}0.193 \\
(0.392)\end{array}$ & $\begin{array}{c}0.726 \\
(0.623)\end{array}$ & $\begin{array}{c}0.190 \\
(0.391)\end{array}$ \\
\hline Residents Per Bed & & & $\begin{array}{r}-0.0686 \\
(0.430)\end{array}$ & $\begin{array}{r}-0.0545 \\
(0.288) \\
\end{array}$ & $\begin{array}{r}-0.0716 \\
(0.432)\end{array}$ & $\begin{array}{l}-0.0553 \\
(0.288) \\
\end{array}$ \\
\hline Sample & non-system & All & non-system & all & non-system & all \\
\hline Include investment returns $\mathrm{i} 2008^{*}$ (year) & $\mathrm{N}$ & $\mathrm{N}$ & $\mathrm{N}$ & $\mathrm{N}$ & Y & Y \\
\hline $\mathrm{N}$ & 5762 & 13031 & 5556 & 12484 & 5556 & 12484 \\
\hline R-sq & 0.368 & 0.372 & 0.386 & 0.395 & 0.386 & 0.395 \\
\hline
\end{tabular}

Unreported covariates include facility and year fixed effects. Regressions are restricted to 2003-2010, excluding 2008. Regressions are weighted by non-Medicare discharges. Standard errors are in parentheses and are clustered on hospital system (with each nonsystem facility its own cluster).

$*$ P-value $<=0.10 * *$ P-value $<=0.05 * * *$ P-value $<=0.001$ 


\section{Table 4}

OLS Estimates of the Impact of Financial Shock on Log Prices High Quality Hospitals

\begin{tabular}{|c|c|c|c|c|c|c|}
\hline & $(1)$ & $(2)$ & (3) & $(4)$ & (5) & $(6)$ \\
\hline investment returns $_{\mathrm{i} 2008} *($ year $>2008)$ & $\begin{array}{c}-0.00467 \\
(0.300)\end{array}$ & $\begin{array}{l}-0.0521 \\
(0.215)\end{array}$ & $\begin{array}{c}0.0913 \\
(0.299)\end{array}$ & $\begin{array}{c}-0.00903 \\
(0.218)\end{array}$ & $\begin{array}{c}-0.813^{* *} \\
(0.395)\end{array}$ & $\begin{array}{c}-0.544 * * \\
(0.270)\end{array}$ \\
\hline $\ln$ (wage) & & & $\begin{array}{c}-0.00131 \\
(0.388)\end{array}$ & $\begin{array}{c}0.236 \\
(0.256)\end{array}$ & $\begin{array}{c}-0.00158 \\
(0.405)\end{array}$ & $\begin{array}{c}0.240 \\
(0.258)\end{array}$ \\
\hline $\ln (\mathrm{CMI})$ & & & $\begin{array}{c}0.187 \\
(0.358)\end{array}$ & $\begin{array}{c}0.319 \\
(0.221)\end{array}$ & $\begin{array}{c}0.144 \\
(0.351)\end{array}$ & $\begin{array}{c}0.320 \\
(0.219)\end{array}$ \\
\hline$\%$ deliveries & & & $\begin{array}{c}0.898 \\
(0.748)\end{array}$ & $\begin{array}{l}0.490^{*} \\
(0.288)\end{array}$ & $\begin{array}{c}1.114 \\
(0.743)\end{array}$ & $\begin{array}{l}0.502 * \\
(0.288)\end{array}$ \\
\hline Lagged Unemployment & & & $\begin{array}{c}0.926 \\
(1.757)\end{array}$ & $\begin{array}{c}0.389 \\
(0.935)\end{array}$ & $\begin{array}{c}1.197 \\
(1.630)\end{array}$ & $\begin{array}{c}0.422 \\
(0.928)\end{array}$ \\
\hline Residents Per Bed & non-system & all & $\begin{array}{c}1.359 * \\
(0.734) \\
\text { non-system }\end{array}$ & $\begin{array}{c}0.625 \\
(0.507) \\
\text { all }\end{array}$ & $\begin{array}{c}1.450 * * \\
(0.701) \\
\text { non-system }\end{array}$ & $\begin{array}{c}0.662 \\
(0.509) \\
\text { all }\end{array}$ \\
\hline Include investment returns $\mathrm{i} 2008 *$ (year) & $\mathrm{N}$ & $\mathrm{N}$ & $\mathrm{N}$ & $\mathrm{N}$ & $\mathrm{Y}$ & $\mathrm{Y}$ \\
\hline $\mathrm{N}$ & 360 & 873 & 332 & 826 & 332 & 826 \\
\hline R-sq & 0.468 & 0.532 & 0.486 & 0.542 & 0.502 & 0.546 \\
\hline investment returns $_{\mathrm{i} 2008} *($ year $>2008)$ & -0.00467 & -0.0521 & 0.0913 & -0.00903 & $-0.813^{* *}$ & $-0.544 * *$ \\
\hline
\end{tabular}

Unreported covariates include facility and year fixed effects. Regressions are restricted to 2003-2010, excluding 2008. Regressions are weighted by non-Medicare discharges. Standard errors are in parentheses and are clustered on hospital system (with each nonsystem facility its own cluster).

$*$ P-value $<=0.10 * *$ P-value $<=0.05 * * *$ P-value $<=0.001$ 
Table 5

OLS Estimates of the Impact of Financial Shocks on Hospitals Costs

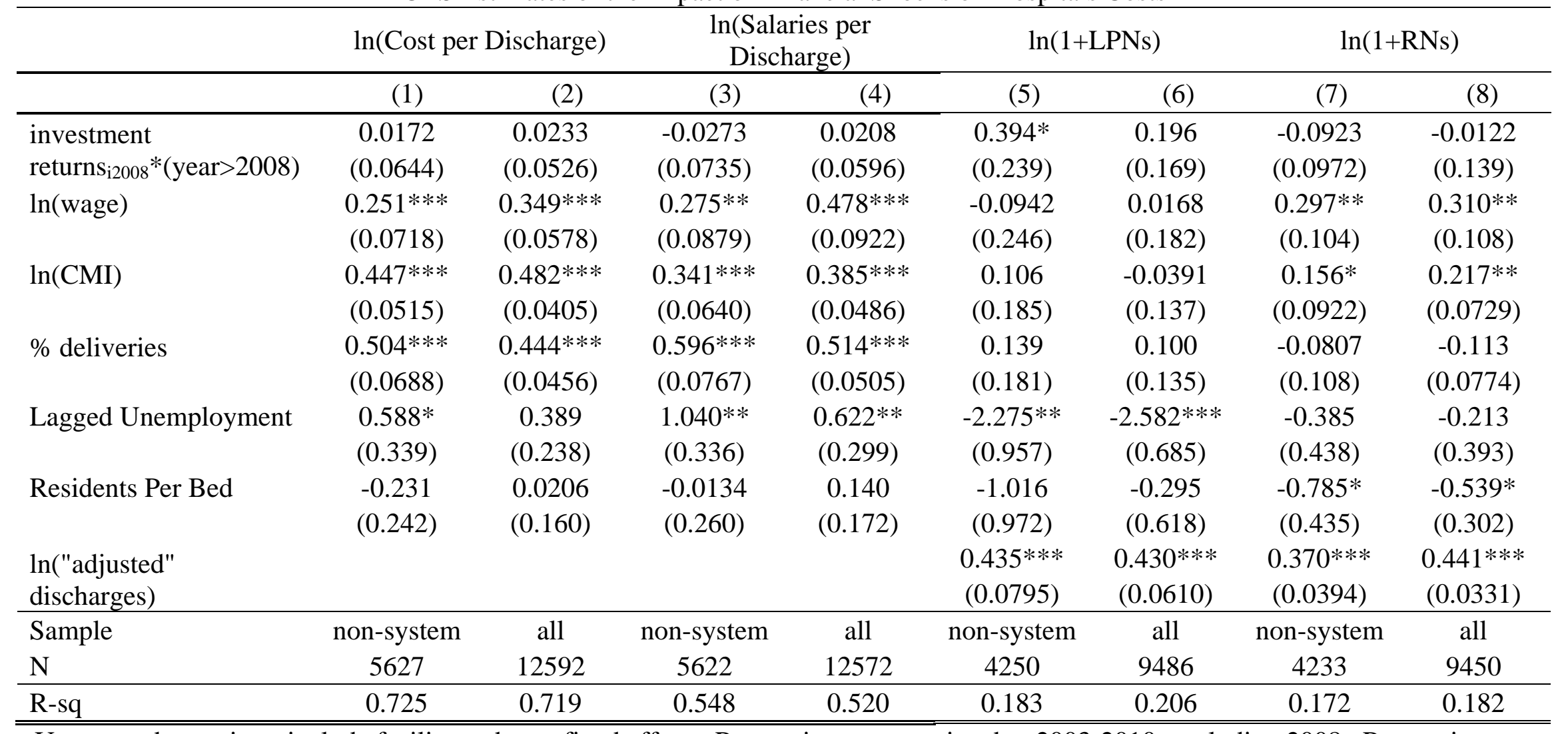

Unreported covariates include facility and year fixed effects. Regressions are restricted to 2003-2010, excluding 2008. Regressions are weighted by non-Medicare discharges. Standard errors are in parentheses and are clustered on hospital system (with each nonsystem facility its own cluster).

$*$ P-value $<=0.10 * *$ P-value $<=0.05 * * *$ P-value $<=0.001$ 


\section{Table 6}

OLS Estimates of the Impact of Financial Shocks on Service Offerings

\begin{tabular}{|c|c|c|c|c|c|c|}
\hline & \multicolumn{6}{|c|}{ Panel A: Less Profitable Services } \\
\hline & \multicolumn{2}{|c|}{ Psychiatric Emergency } & \multicolumn{2}{|c|}{ Trauma } & \multicolumn{2}{|c|}{ Alcohol and Drug } \\
\hline & $(1)$ & $(2)$ & $(3)$ & $(4)$ & $(5)$ & $(6)$ \\
\hline investment returns $\mathrm{i}_{\mathrm{i} 2008} *($ year $>2008)$ & $(0.135)$ & $(0.106)$ & $(0.148)$ & $(0.0978)$ & $(0.130)$ & $(0.0935)$ \\
\hline \multirow[t]{2}{*}{$\ln$ (wage) } & $0.400 *$ & 0.127 & 0.0866 & -0.0760 & 0.0821 & -0.0681 \\
\hline & $(0.156)$ & $(0.114)$ & $(0.195)$ & $(0.139)$ & $(0.132)$ & $(0.0860)$ \\
\hline Lagged Unemployment & $(0.519)$ & $(0.430)$ & $(0.669)$ & $(0.457)$ & $(0.412)$ & $(0.272)$ \\
\hline Sample & non-system & All & non-system & all & non-system & all \\
\hline $\mathrm{N}$ & 5844 & 13260 & 5845 & 13262 & 5845 & 13263 \\
\hline \multirow[t]{2}{*}{ R-sq } & 0.005 & 0.001 & 0.008 & 0.008 & 0.008 & 0.005 \\
\hline & \multicolumn{6}{|c|}{ Panel B: More Profitable Services } \\
\hline \multirow[t]{2}{*}{$\ln$ (wage) } & 0.0348 & 0.00549 & 0.219 & 0.134 & -0.147 & -0.186 \\
\hline & $(0.143)$ & $(0.0899)$ & $(0.207)$ & $(0.167)$ & $(0.166)$ & $(0.114)$ \\
\hline \multirow[t]{2}{*}{ Lagged Unemployment } & $1.329 * * *$ & $0.651 * *$ & 0.850 & 0.331 & -0.0182 & 0.0406 \\
\hline & $(0.423)$ & $(0.317)$ & $(0.780)$ & $(0.497)$ & $(0.620)$ & $(0.431)$ \\
\hline Sample & non-system & All & non-system & all & non-system & All \\
\hline $\mathrm{N}$ & 5844 & 13260 & 5845 & 13262 & 5845 & 13263 \\
\hline R-sq & 0.005 & 0.001 & 0.008 & 0.008 & 0.008 & 0.005 \\
\hline
\end{tabular}

Unreported covariates include facility and year fixed effects. Regressions are restricted to 2003-2011, excluding 2008. Regressions are unweighted. Standard errors are in parentheses and are clustered on system (with each non-system facility its own cluster).

$*$ P-value $<=0.10 * *$ P-value $<=0.05 * * *$ P-value $<=0.001$ 


\section{Table 7}

Cox Proportional Hazard Model Estimates of the Effect of 2008 Investment Losses on EMR Adoption

\begin{tabular}{|c|c|c|c|c|}
\hline & \multicolumn{2}{|c|}{$\begin{array}{c}\text { Computerized Physician } \\
\text { Order Entry } \\
\end{array}$} & \multicolumn{2}{|c|}{ Physician Documentation } \\
\hline & $(1)$ & $(2)$ & (3) & (4) \\
\hline \multirow{2}{*}{ investment returns $\mathrm{i}_{2008} *($ year $==2004)$} & 0.113 & 0.876 & & \\
\hline & $(-1.55)$ & $(-0.12)$ & & \\
\hline \multirow[t]{2}{*}{ investment returns $\mathrm{i}_{2008} *($ year==2005) } & 0.131 & 0.268 & & \\
\hline & $(-1.28)$ & $(-1.20)$ & & \\
\hline \multirow{2}{*}{ investment returns $\mathrm{i}_{\mathrm{i} 2008} *($ year $==2006)$} & 0.167 & 0.229 & 0.194 & 2.418 \\
\hline & $(-0.86)$ & $(-1.16)$ & $(-1.00)$ & $(0.76)$ \\
\hline \multirow{2}{*}{ investment returns $\mathrm{i}_{\mathrm{i} 2008} *($ year==2007) } & $0.0273 *$ & $0.0396 * *$ & $0.0317^{* *}$ & 0.255 \\
\hline & $(-1.89)$ & $(-2.55)$ & $(-2.05)$ & $(-1.11)$ \\
\hline \multirow{2}{*}{ investment returns $\mathrm{i}_{\mathrm{i} 2008} *($ year $==2008)$} & 18.46 & 2.567 & 0.262 & 0.128 \\
\hline & $(1.21)$ & $(0.57)$ & $(-0.68)$ & $(-1.47)$ \\
\hline \multirow[t]{2}{*}{ investment returns $\mathrm{i}_{\mathrm{i} 2008} *(\mathrm{year}==2009)$} & $0.00380^{* *}$ & $0.00301^{* * *}$ & $0.0218 * *$ & $0.00751 * * *$ \\
\hline & $(-2.64)$ & $(-3.92)$ & $(-2.00)$ & $(-3.75)$ \\
\hline \multirow[t]{2}{*}{ investment returns $\mathrm{i}_{\mathrm{i} 2008} *($ year $==2010)$} & 0.592 & 0.111 & $0.0264 * *$ & $0.0957^{*}$ \\
\hline & $(-0.30)$ & $(-1.62)$ & $(-2.14)$ & $(-1.85)$ \\
\hline \multirow[t]{2}{*}{ investment returns $\mathrm{i}_{2008} *($ year==2011) } & 0.719 & 0.202 & 0.276 & $0.00137 * * *$ \\
\hline & $(-0.13)$ & $(-0.82)$ & $(-0.49)$ & $(-3.75)$ \\
\hline Sample & non-system & all & non-system & all \\
\hline Number of subject $\mathrm{x}$ years & 3295 & 7016 & 2709 & 5655 \\
\hline Number of subjects & 736 & 1596 & 661 & 1443 \\
\hline Number of adoptions & 569 & 1296 & 413 & 999 \\
\hline
\end{tabular}

Reported coefficients are Hazard Ratios. Run using “exact” method for accounting for ties in Stata.

$\mathrm{P}$-values are reported in parentheses.

* P-value $<=0.10 * *$ P-value $<=0.05 * * *$ P-value $<=0.001$ 
Table 8

Effect of 2008 Investment Losses on Advanced HIT Adoption (Cox Model)

\begin{tabular}{|c|c|c|c|c|c|c|c|c|}
\hline & \multicolumn{4}{|c|}{ Computerized Physician Order Entry } & \multicolumn{4}{|c|}{ Physician Documentation } \\
\hline & $(1)$ & $(2)$ & (3) & (4) & (5) & (6) & $(7)$ & (8) \\
\hline \multirow[t]{2}{*}{ investment returns $_{\mathrm{i} 2008}$} & $0.0959 * *$ & $0.251 * *$ & $0.174 * *$ & 0.375 & $0.0813 * *$ & 0.906 & $0.102 *$ & 1.096 \\
\hline & $(-2.77)$ & $(-2.32)$ & $(-2.02)$ & $(-1.62)$ & $(-2.13)$ & $(-0.11)$ & $(-1.90)$ & $(0.11)$ \\
\hline \multirow{2}{*}{ investment returns $\mathrm{i}_{\mathrm{i} 2008} *($ year $==2008)$} & $192.0 * *$ & 12.88 & $290.6 * *$ & 13.66 & 3.227 & 0.153 & 8.322 & 0.208 \\
\hline & $(2.05)$ & $(1.44)$ & $(2.13)$ & $(1.44)$ & $(0.51)$ & $(-1.14)$ & $(0.89)$ & $(-0.93)$ \\
\hline \multirow[t]{2}{*}{ investment returns ${ }_{\mathrm{i} 2008} *($ year>2008) } & 1.425 & $0.154 *$ & 1.404 & $0.147^{*}$ & 0.487 & $0.0204 * *$ & 0.989 & $0.0320 * *$ \\
\hline & $(0.24)$ & $(-1.74)$ & $(0.23)$ & $(-1.75)$ & $(-0.44)$ & $(-3.27)$ & $(-0.01)$ & $(-2.85)$ \\
\hline \multirow[t]{2}{*}{ ARRA } & & & $0.730 * * *$ & $0.681^{* * *}$ & & & 0.843 & 0.868 \\
\hline & & & $(-3.45)$ & $(-4.88)$ & & & $(-1.55)$ & $(-1.47)$ \\
\hline \multirow[t]{2}{*}{ ARRA*(year==2008) } & & & 1.061 & 1.222 & & & 0.831 & 0.901 \\
\hline & & & $(0.32)$ & $(1.20)$ & & & $(-0.95)$ & $(-0.61)$ \\
\hline \multirow[t]{2}{*}{ ARRA*(year>2008) } & & & 1.131 & $1.291 * *$ & & & 0.854 & 0.865 \\
\hline & & & $(0.97)$ & $(2.27)$ & & & $(-1.11)$ & $(-1.14)$ \\
\hline \multirow[t]{2}{*}{ ACGME } & & & $1.411^{* *}$ & $1.308 * *$ & & & 0.852 & 1.078 \\
\hline & & & $(2.32)$ & (3.18) & & & $(-0.75)$ & $(0.63)$ \\
\hline \multirow[t]{2}{*}{ ACGME*(year==2008) } & & & 0.775 & 1.104 & & & 1.179 & 0.993 \\
\hline & & & $(-0.64)$ & $(0.41)$ & & & $(0.42)$ & $(-0.03)$ \\
\hline \multirow[t]{2}{*}{ ACGME*(year>2008) } & & & 0.684 & 1.019 & & & 1.149 & 1.222 \\
\hline & & & $(-1.47)$ & $(0.12)$ & & & $(0.48)$ & $(1.20)$ \\
\hline Sample & $\begin{array}{c}\text { non- } \\
\text { system }\end{array}$ & all & $\begin{array}{c}\text { non- } \\
\text { system }\end{array}$ & all & $\begin{array}{c}\text { non- } \\
\text { system }\end{array}$ & all & $\begin{array}{c}\text { non- } \\
\text { system }\end{array}$ & all \\
\hline $\mathrm{N}$ & 3291 & 7016 & 3291 & 7016 & 2707 & 5655 & 2707 & 5655 \\
\hline N_sub & 735 & 1596 & 735 & 1596 & 660 & 1443 & 660 & 1443 \\
\hline N_fail & 568 & 1296 & 568 & 1296 & 412 & 999 & 412 & 999 \\
\hline
\end{tabular}

Reported coefficients are Hazard Ratios. T-statistics are reported in parentheses. Regressions with system facilities also include as controls interactions between system size category and the three time categories. 


\section{Table 9}

Weibull Model Estimates of the Effect of 2008 Investment Losses on Advanced HIT Adoption

\begin{tabular}{|c|c|c|c|c|c|c|c|c|}
\hline & \multicolumn{4}{|c|}{ Computerized Physician Order Entry } & \multicolumn{4}{|c|}{ Physician Documentation } \\
\hline & $(1)$ & $(2)$ & $(3)$ & $(4)$ & $(5)$ & $(6)$ & $(7)$ & $(8)$ \\
\hline investment returns $\mathrm{i}_{\mathrm{i} 2008}$ & $\begin{array}{c}0.0398 * * * \\
(-4.22)\end{array}$ & $\begin{array}{c}0.0883 * * \\
(-3.07)\end{array}$ & $\begin{array}{c}0.116 * * \\
(-2.69)\end{array}$ & $\begin{array}{l}0.240 * \\
(-1.68)\end{array}$ & $\begin{array}{c}0.00184 * * * \\
(-5.74)\end{array}$ & $\begin{array}{c}0.0177 * * \\
(-2.93)\end{array}$ & $\begin{array}{c}0.00403 * * * \\
(-4.43)\end{array}$ & $\begin{array}{c}0.0633 * * \\
(-2.11)\end{array}$ \\
\hline investment returns $_{\mathrm{i} 2008} *($ year $==2008)$ & $\begin{array}{c}2598.0 * * * \\
(3.51)\end{array}$ & $\begin{array}{c}413.4^{* *} \\
(3.02)\end{array}$ & $\begin{array}{c}903.9 * * \\
(2.61)\end{array}$ & $\begin{array}{c}69.18 * * \\
(2.07)\end{array}$ & $\begin{array}{c}210.4^{* *} \\
(3.20)\end{array}$ & $\begin{array}{l}284.9 \\
(1.15)\end{array}$ & $\begin{array}{c}314.0 * * \\
(2.52)\end{array}$ & $\begin{array}{l}15.47 \\
(1.09)\end{array}$ \\
\hline investment returns ${ }_{\mathrm{i} 2008} *($ year $>2008)$ & $\begin{array}{c}7.905^{* *} \\
(2.08)\end{array}$ & $\begin{array}{l}3.868 \\
(1.29)\end{array}$ & $\begin{array}{l}5.361 \\
(1.59)\end{array}$ & $\begin{array}{l}1.023 \\
(0.02)\end{array}$ & $\begin{array}{c}203.6 * * * \\
(4.02)\end{array}$ & $\begin{array}{c}35.50 * * \\
(1.96)\end{array}$ & $\begin{array}{c}212.3^{* *} \\
(2.98)\end{array}$ & $\begin{array}{l}8.763 \\
(1.07)\end{array}$ \\
\hline ARRA & & & $\begin{array}{c}0.745^{* * *} \\
(-3.77)\end{array}$ & $\begin{array}{c}0.590 * * * \\
(-5.07)\end{array}$ & & & $\begin{array}{c}1.210 * * \\
(2.00)\end{array}$ & $\begin{array}{c}0.512 * * * \\
(-3.74)\end{array}$ \\
\hline ARRA* $($ year $==2008)$ & & & $\begin{array}{c}0.898 \\
(-0.92)\end{array}$ & $\begin{array}{c}1.626 * * \\
(2.91)\end{array}$ & & & $\begin{array}{c}0.567 * * * \\
(-3.58)\end{array}$ & $\begin{array}{c}1.751 * * \\
(2.07)\end{array}$ \\
\hline ARRA*(year>2008) & & & $\begin{array}{l}1.124 \\
(1.43)\end{array}$ & $\begin{array}{c}1.606 * * * \\
(3.84)\end{array}$ & & & $\begin{array}{c}0.418 * * * \\
(-4.67)\end{array}$ & $\begin{array}{c}1.804 * * \\
(3.07)\end{array}$ \\
\hline ACGME & & & $\begin{array}{c}1.550 * * * \\
(3.49)\end{array}$ & $\begin{array}{c}1.353 * * \\
(3.14)\end{array}$ & & & $\begin{array}{c}1.813 * * \\
(2.62)\end{array}$ & $\begin{array}{c}1.478 * * \\
(3.09)\end{array}$ \\
\hline $\mathrm{ACGME}^{*}($ year$==2008)$ & & & $\begin{array}{c}0.513 * * \\
(-2.45)\end{array}$ & $\begin{array}{c}0.825 \\
(-0.90)\end{array}$ & & & $\begin{array}{l}0.511 * \\
(-1.84)\end{array}$ & $\begin{array}{c}0.626 \\
(-1.55)\end{array}$ \\
\hline ACGME*(year>2008) & & & $\begin{array}{c}0.577 * * * \\
(-3.32)\end{array}$ & $\begin{array}{c}0.834 \\
(-1.29) \\
\end{array}$ & & & $\begin{array}{c}0.308 * * \\
(-3.24)\end{array}$ & $\begin{array}{c}0.676 \\
(-1.57) \\
\end{array}$ \\
\hline Sample & $\begin{array}{c}\text { non- } \\
\text { system }\end{array}$ & all & $\begin{array}{c}\text { non- } \\
\text { system }\end{array}$ & all & non-system & all & non-system & all \\
\hline $\mathrm{N}$ & 3291 & 7016 & 3291 & 7016 & 2707 & 5655 & 2707 & 5655 \\
\hline N_sub & 735 & 1596 & 735 & 1596 & 660 & 1443 & 660 & 1443 \\
\hline N_fail & 568 & 1296 & 568 & 1296 & 412 & 999 & 412 & 999 \\
\hline
\end{tabular}

Unreported covariates in specifications with systems include an interaction between system membership and the pre, transition and post periods. Reported coefficients are Hazard Ratios. P-values are reported in parentheses. Standard are clustered on hospital system (with each non-system facility its own cluster).

$*$ P-value $<=0.10 * *$ P-value $<=0.05 * * *$ P-value $<=0.001$ 


\section{Figure 1a}

Investment Returns of Hospitals Compared to the S\&P 500

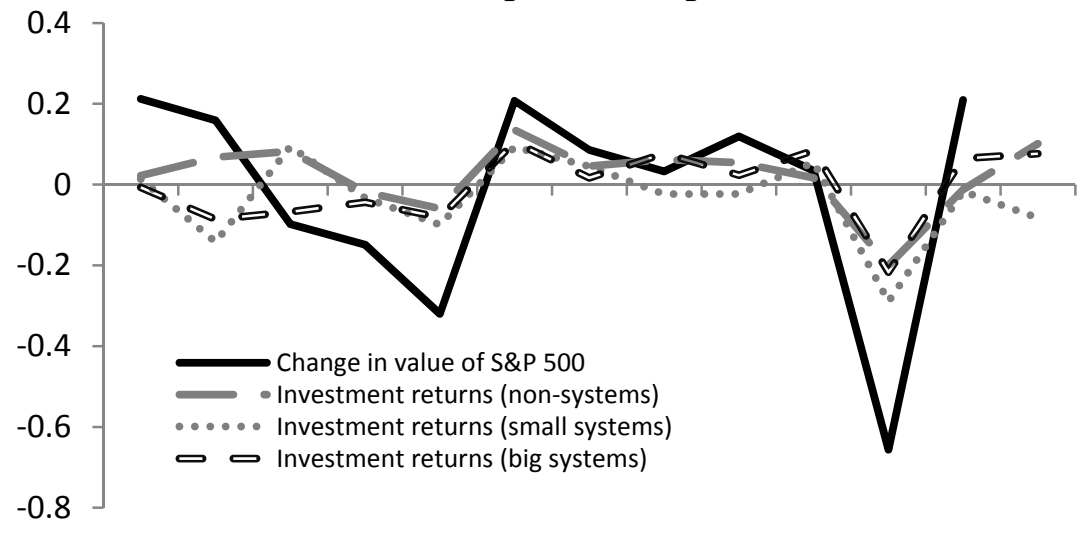

1998199920002001200220032004200520062007200820092010

Notes: S\&P 500 value is measured as of year end. Hospital investment returns are

measured as realized \& unrealized investment returns divided by total investment assets as of prior year. Hospital investment returns are weighted by prior year end investments, so give the average return on a dollar. Hospital investment returns are censored at the 1st and 99th percentile by year.

\section{Figure 1b}

Non- systems

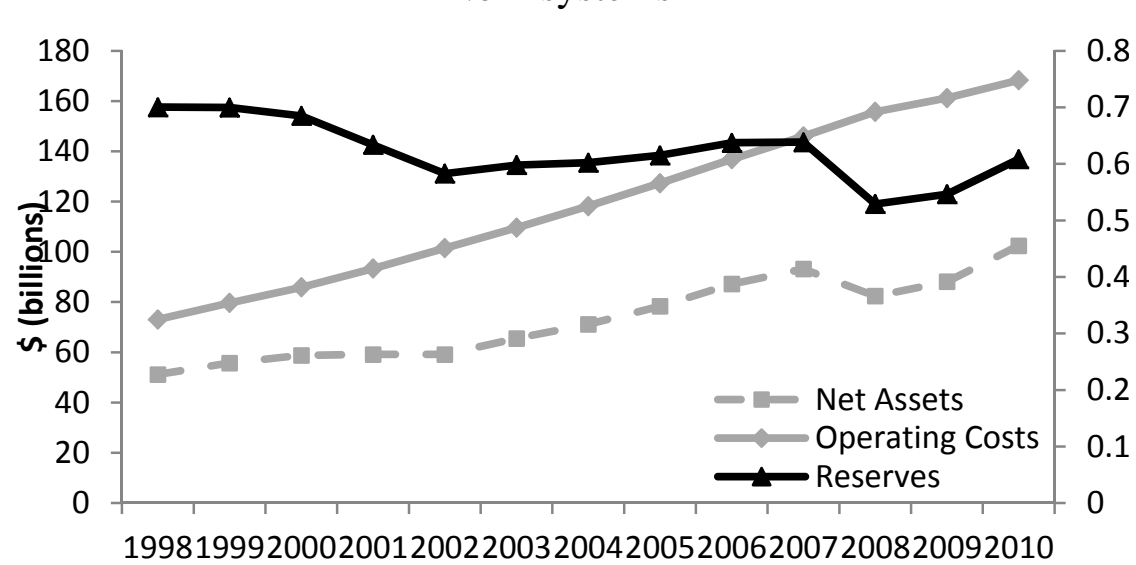

Notes: Total fund balances and operating costs for a balanced panel of 535 non-system hospitals present in all years from 1998-2010.
Figure 1c

Small Systems

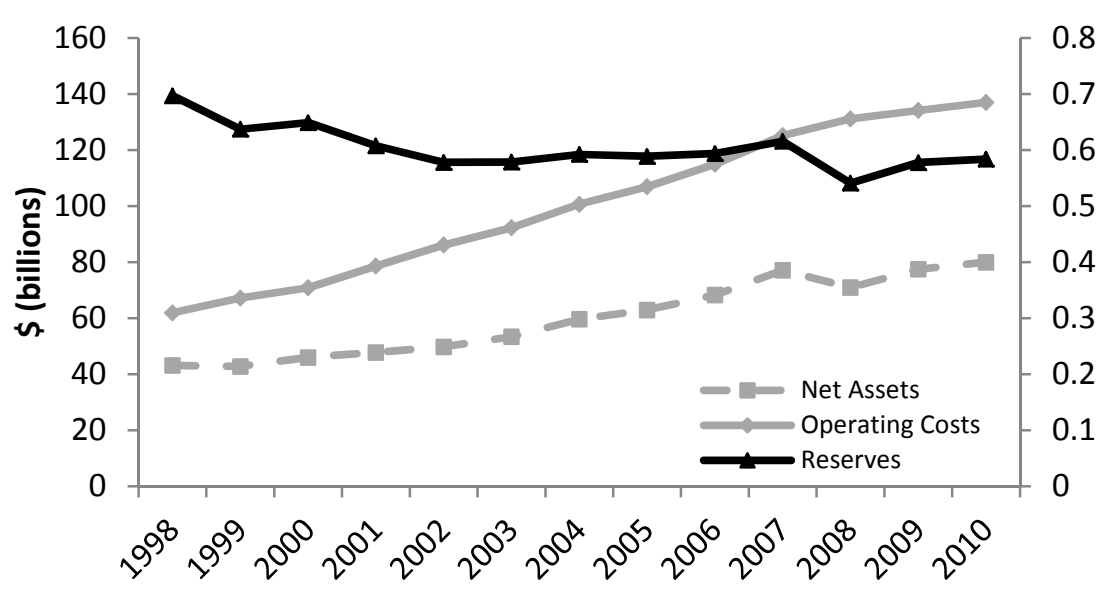

Notes: Total fund balances and operating costs for a balanced panel of 535 hospitals present in all years from 1998-2010 and 212 systems with under 7 hospitals in 2007 (with a mean of 2.47 hospitals per system year).

\section{Figure 1d}

Big Systems

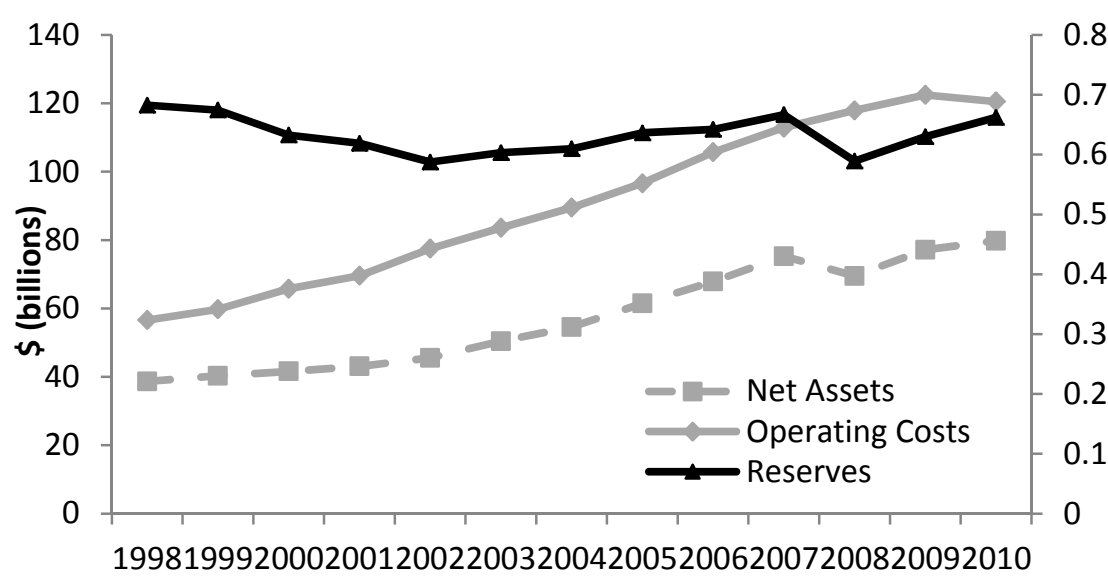

Notes: Total fund balances and operating costs for a balanced panel of 42 systems with 7 or more hospitals in 2007 (average of 14 hospitals in 2007), present in all years from 1998-2010. 
Figure 2a

OLS Estimates of Impact of Investment Losses on Reserves Non-System Hospitals

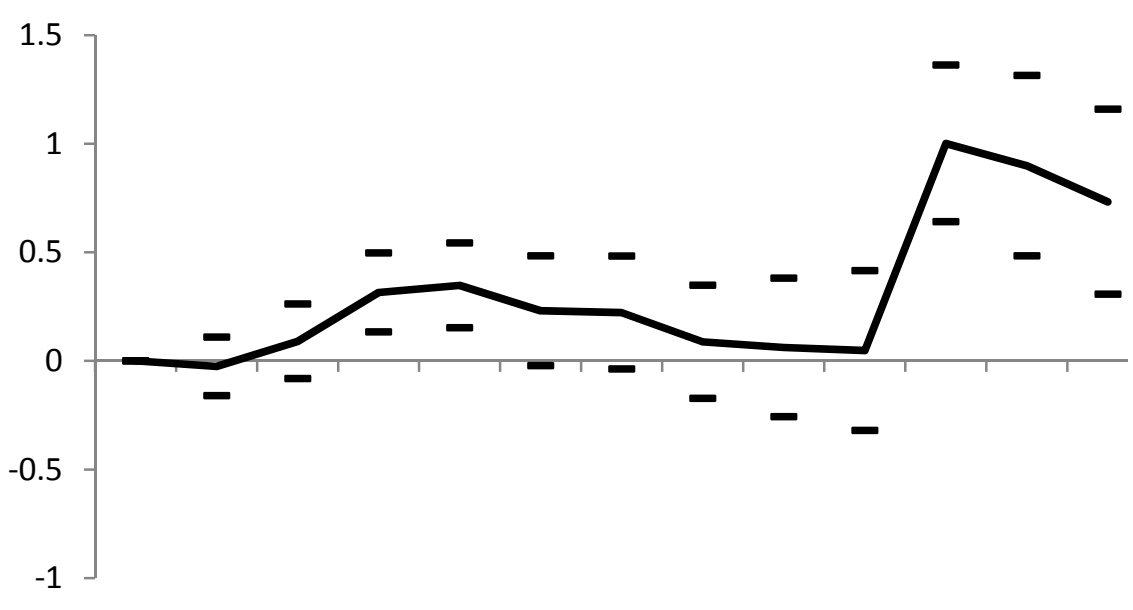

199819992000200120022003200420052006200720082009201

Figure $2 \mathbf{b}$

OLS Estimates of Impact of Investment Losses on Reserves Small System Hospitals

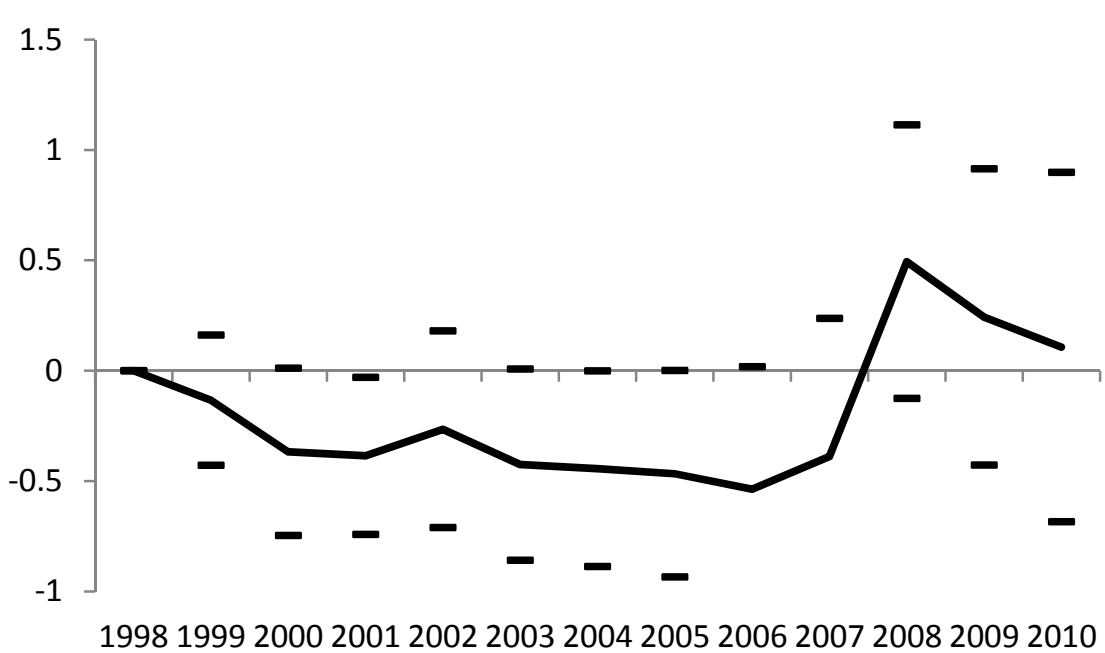

Figure 2c

OLS Estimates of Impact of Investment Losses on Reserves Large System Hospitals

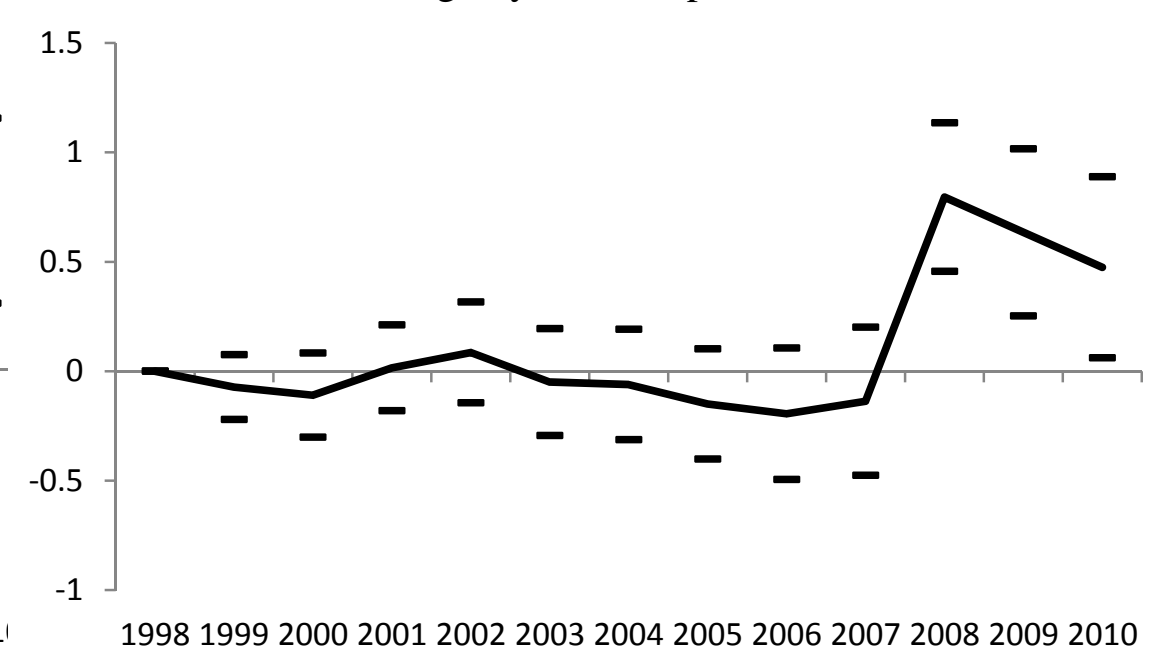

Figure 2d

OLS Estimates of Impact of Investment Losses on Reserves All Hospitals

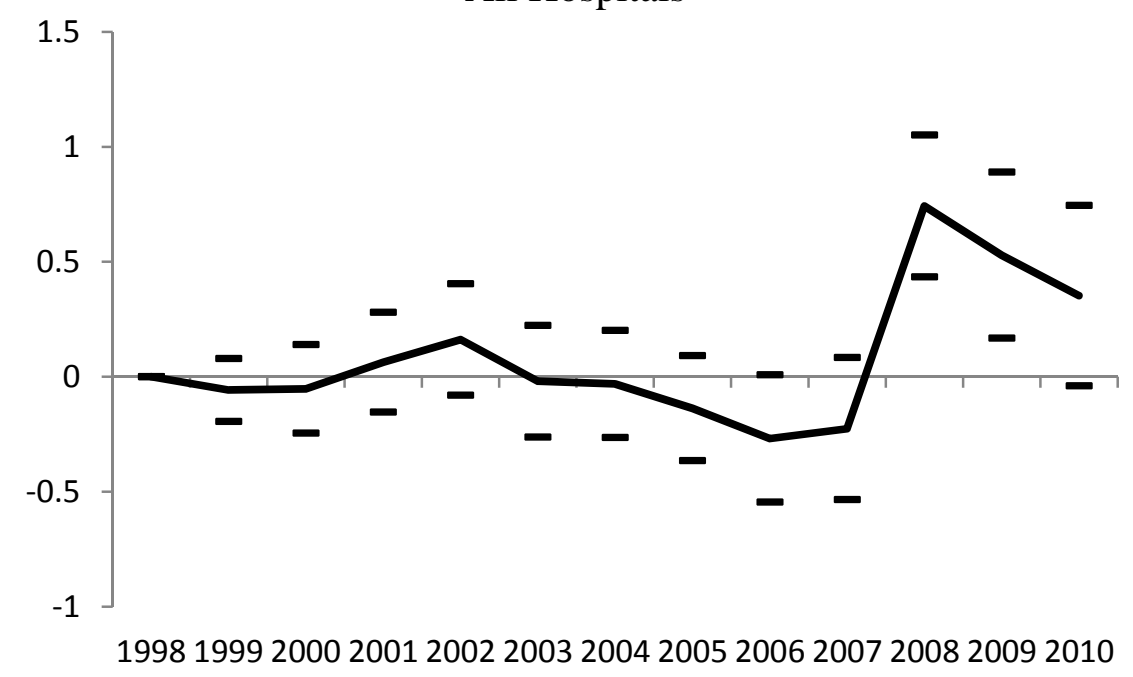


Figure 3a

OLS Estimates of Impact of Investment Losses on Non-Medicare Prices, Non-System Hospitals
Figure 3c

OLS Estimates of Impact of Investment Losses on Non-Medicare Prices, Non-System Hospitals Based High Quality Status

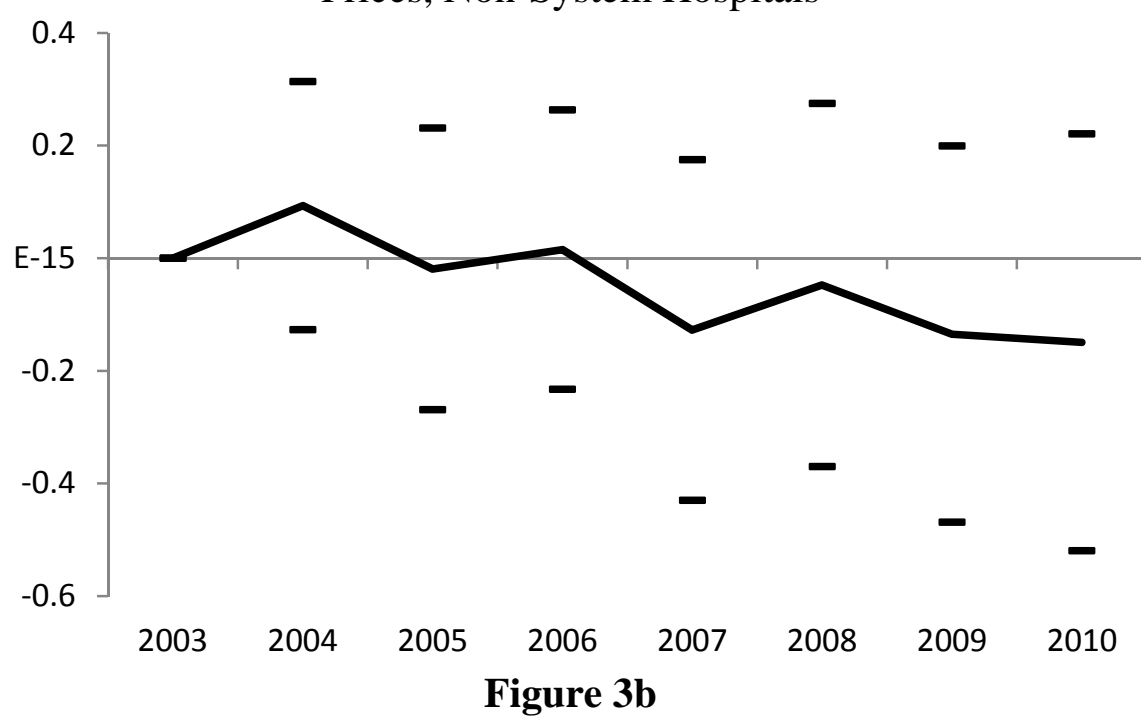

OLS Estimates of Impact of Investment Losses on Non-Medicare Prices, All Hospitals
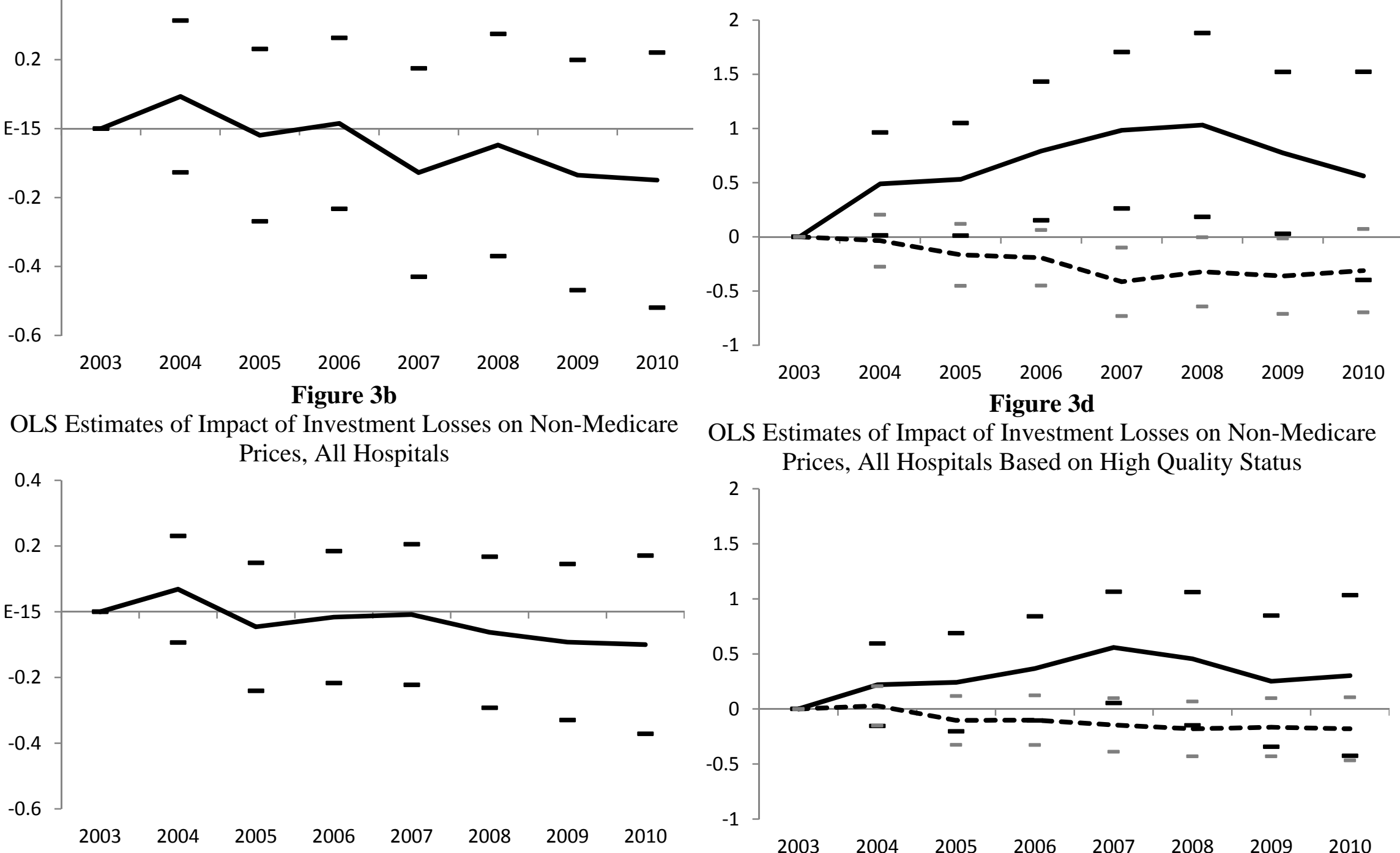

OLS Estimates of Impact of Investment Losses on Non-Medicare Prices, All Hospitals Based on High Quality Status

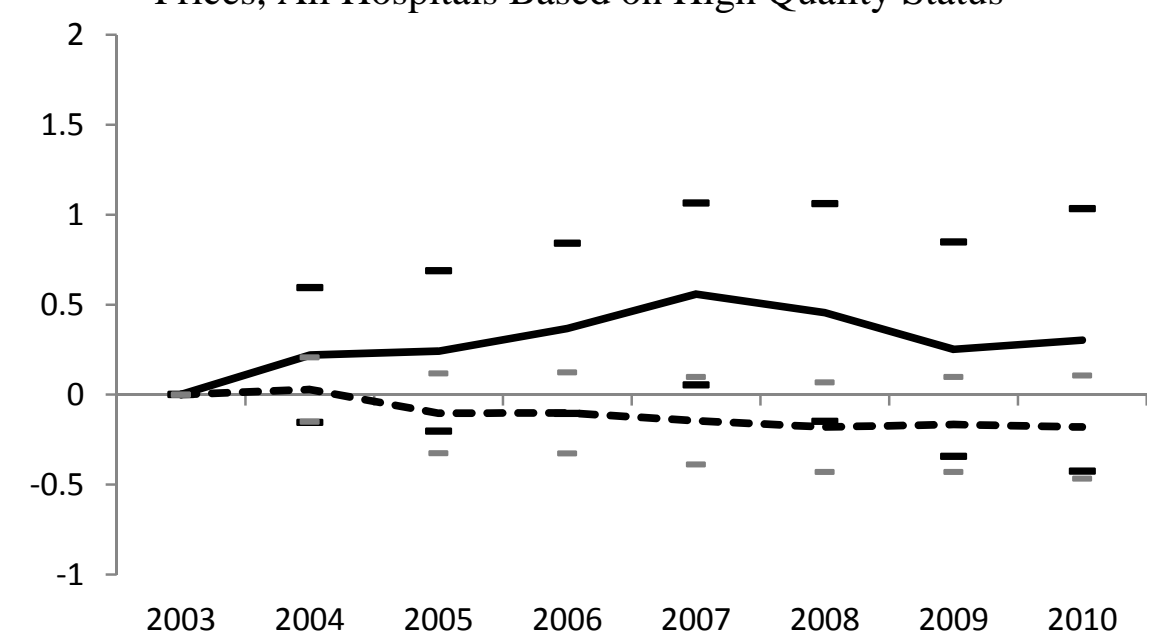


Figure 4a

OLS Estimates of Impact of Investment Losses on Non-Medicare Prices, Non System Hospitals in Third Tercile of Quality

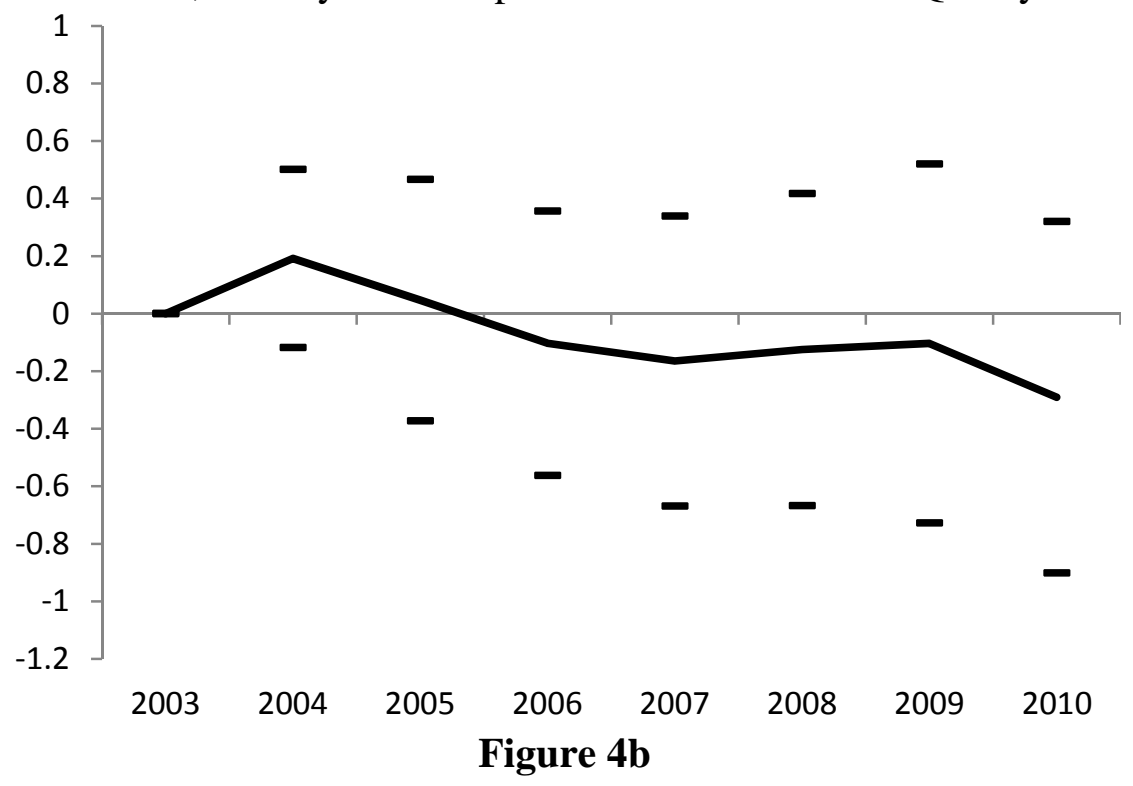

OLS Estimates of Impact of Investment Losses on Non-Medicare Prices, Non System Hospitals in First Tercile of Quality

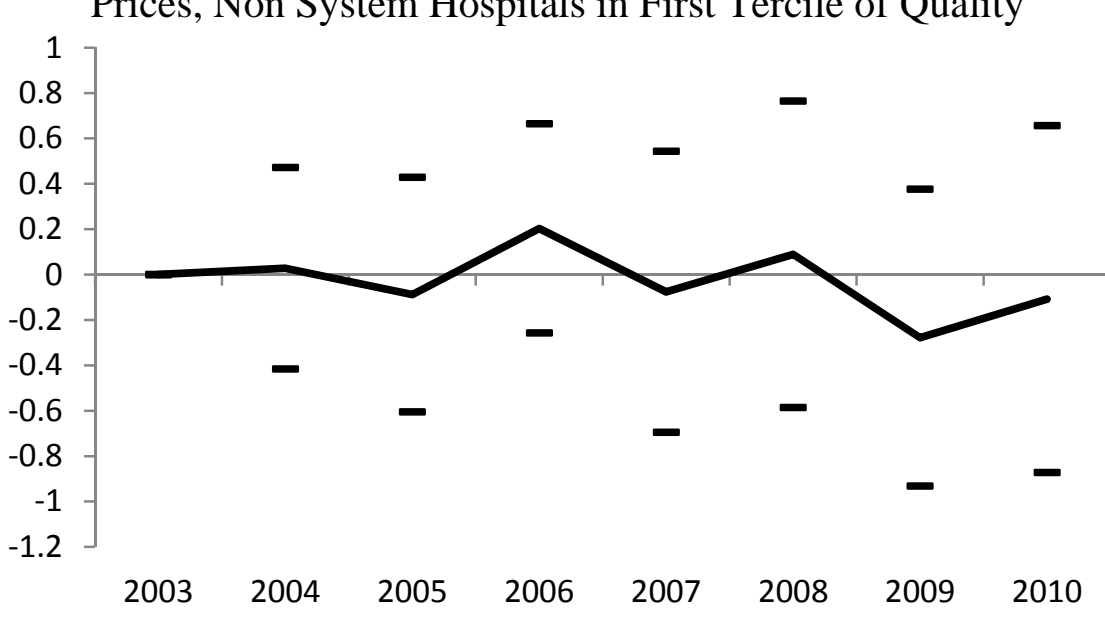

Figure 4c

OLS Estimates of Impact of Investment Losses on Non-Medicare Prices, All Hospitals in Third Tercile of Quality

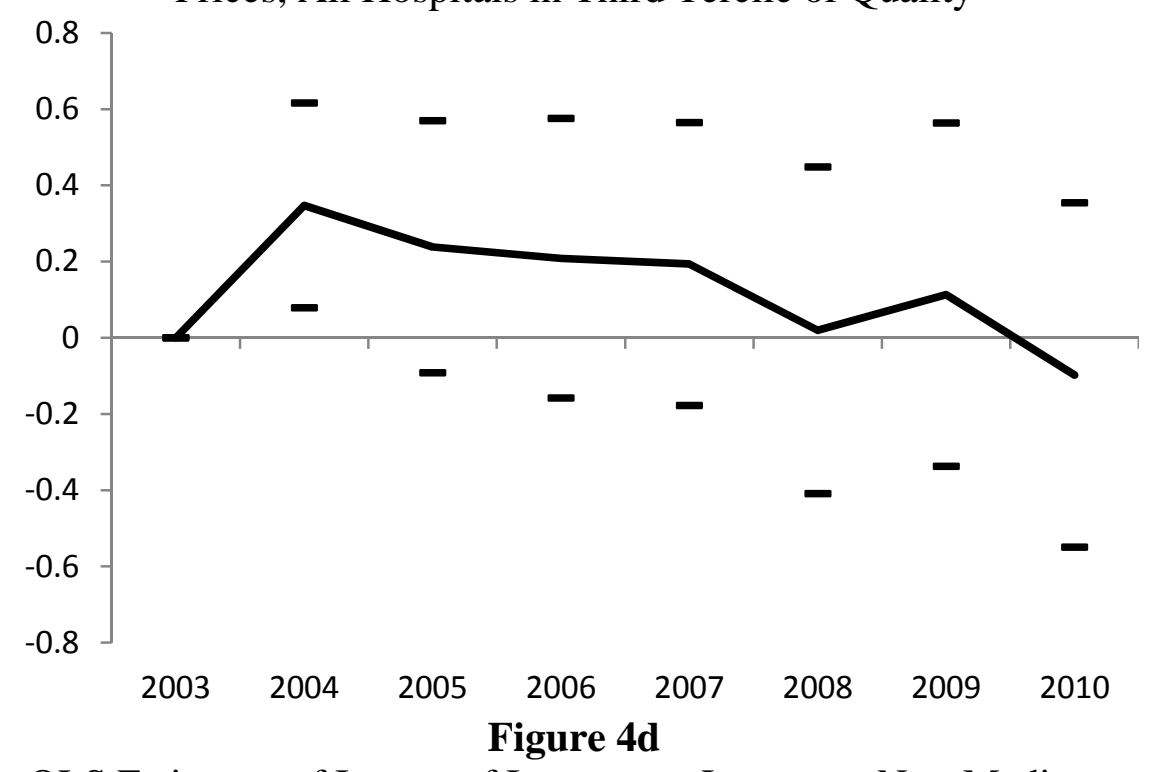

OLS Estimates of Impact of Investment Losses on Non-Medicare Prices, All Hospitals in First Tercile of Quality

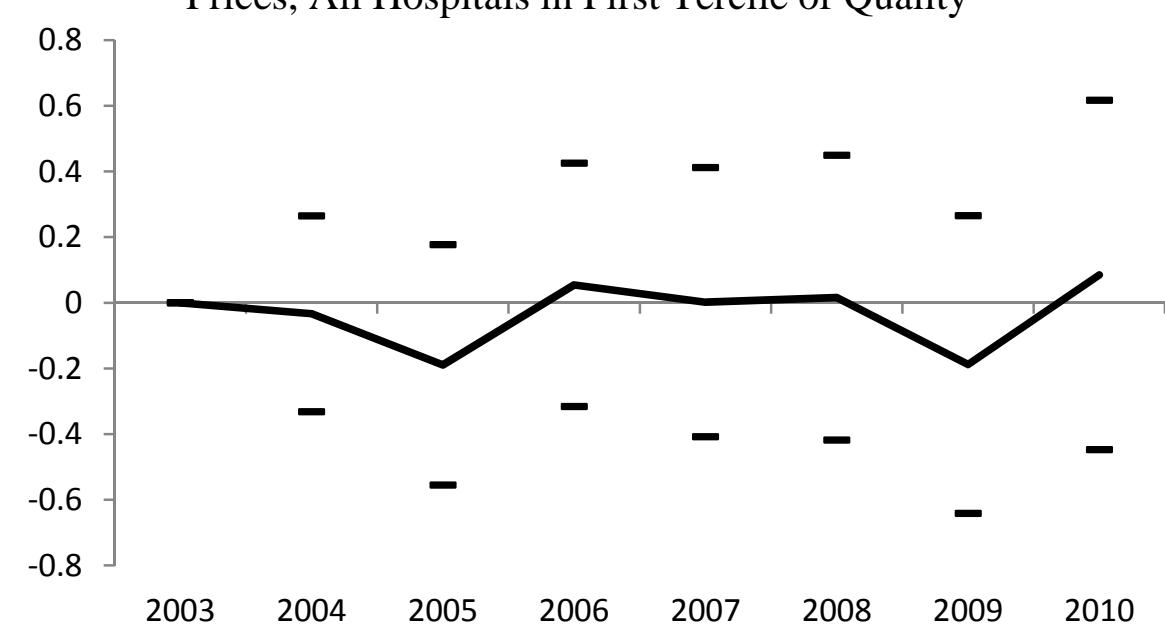


Figure 5a

OLS Estimates of Impact of Investment Losses on Costs per Discharge, Non-System Hospitals

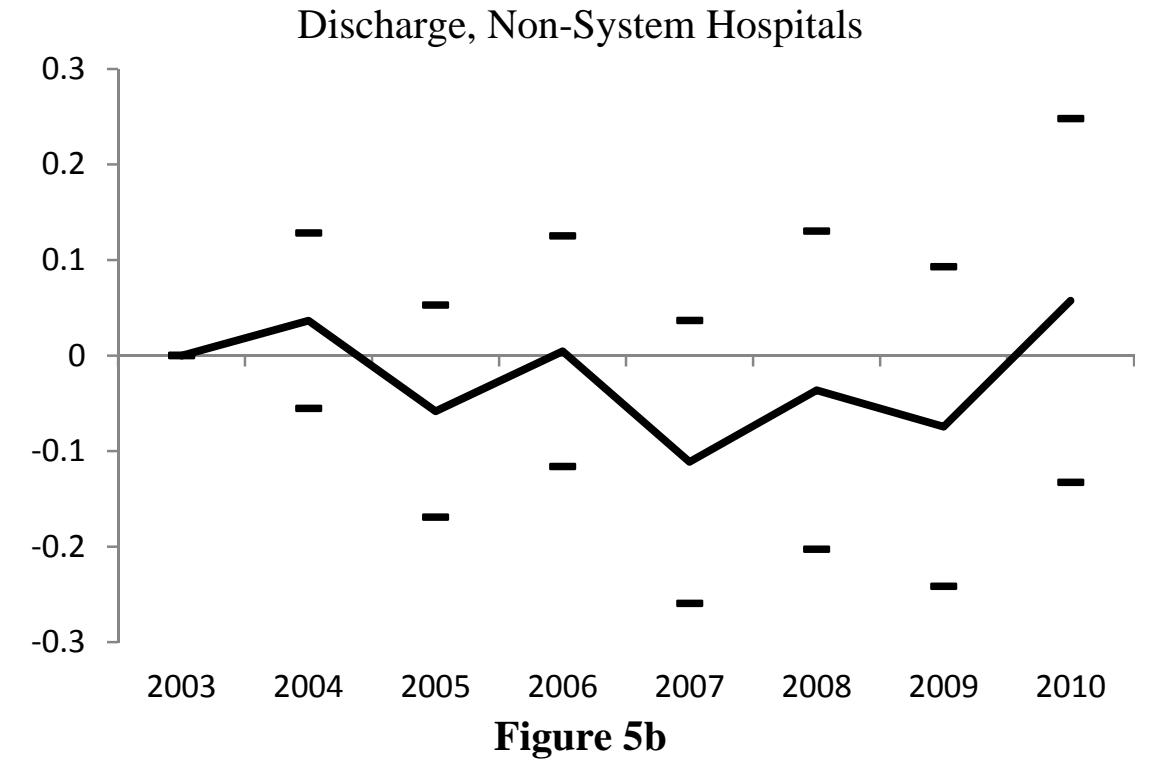

OLS Estimates of Impact of Investment Losses on Costs per Discharge, All Hospitals

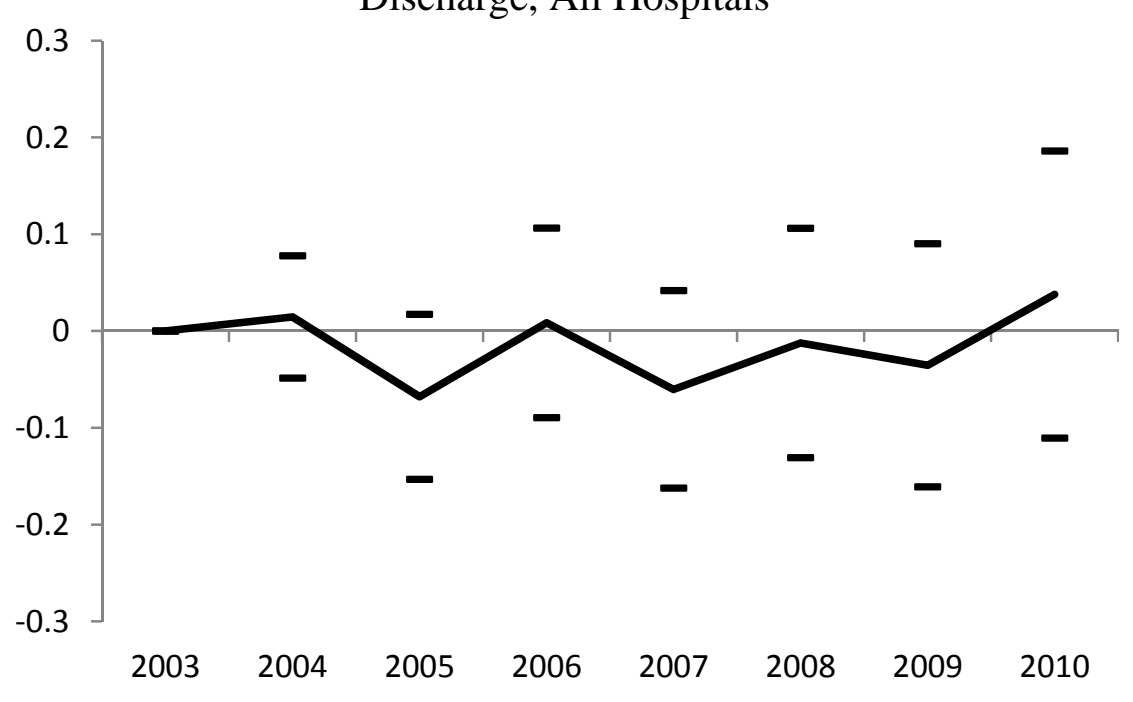

\section{Figure 5c}

OLS Estimates of Impact of Investment Losses on Salaries per Discharge, Non-System Hospitals

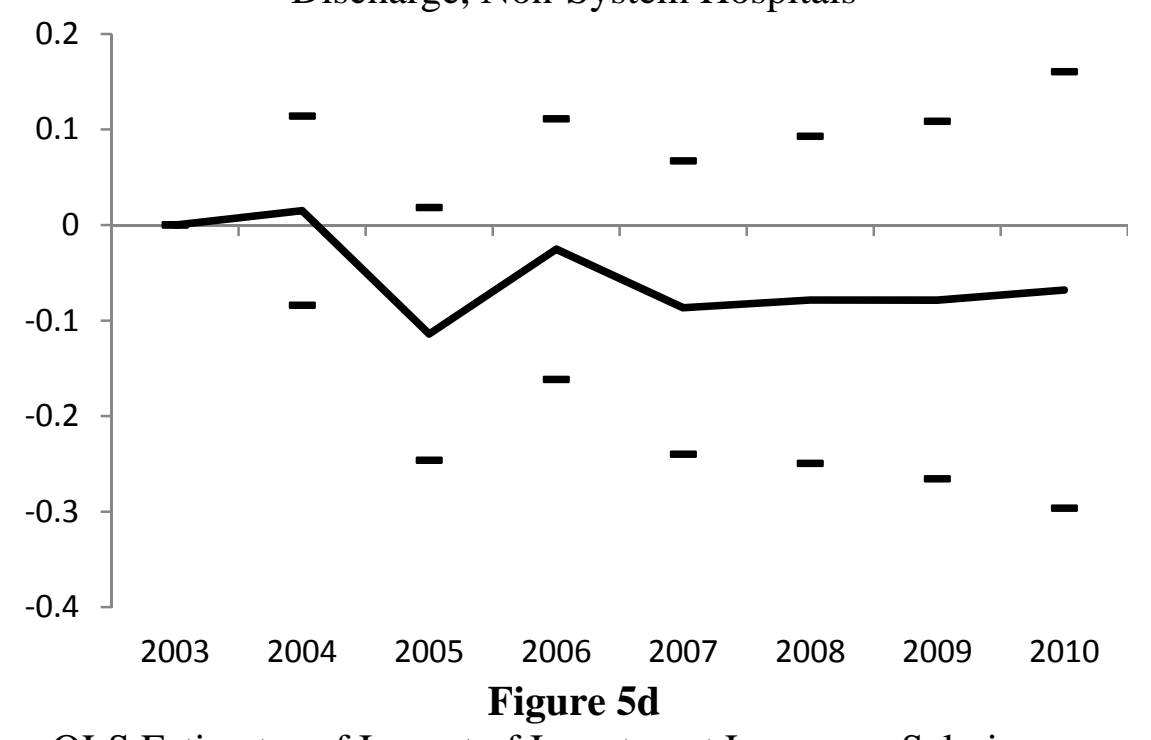

OLS Estimates of Impact of Investment Losses on Salaries per Discharge, Non-System Hospitals

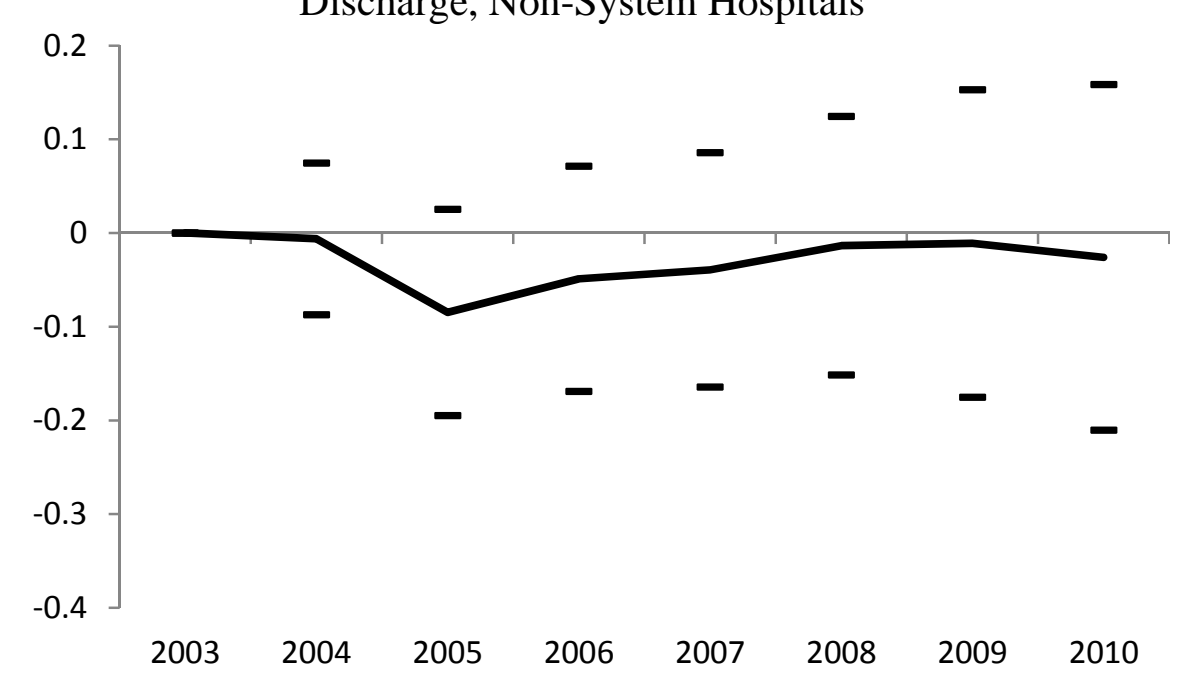


Figure 6a

OLS Estimates of Impact of Investment Losses on Registered Nurses, Non-System Hospitals

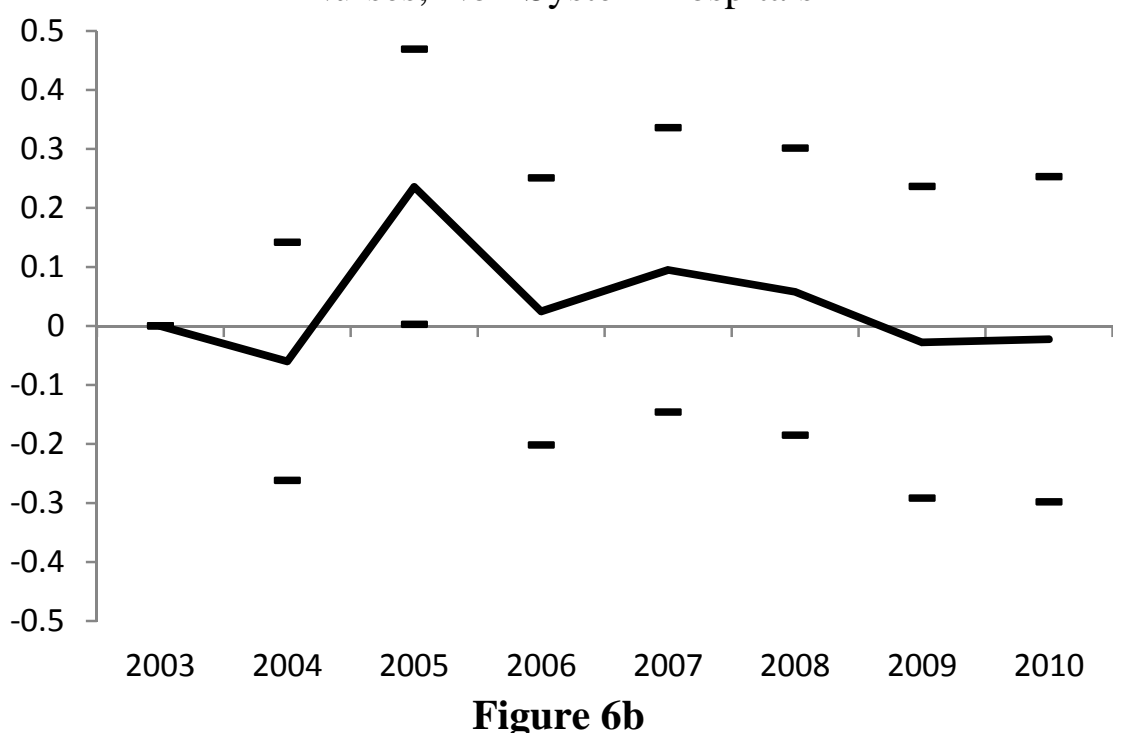

OLS Estimates of Impact of Investment Losses on Registered

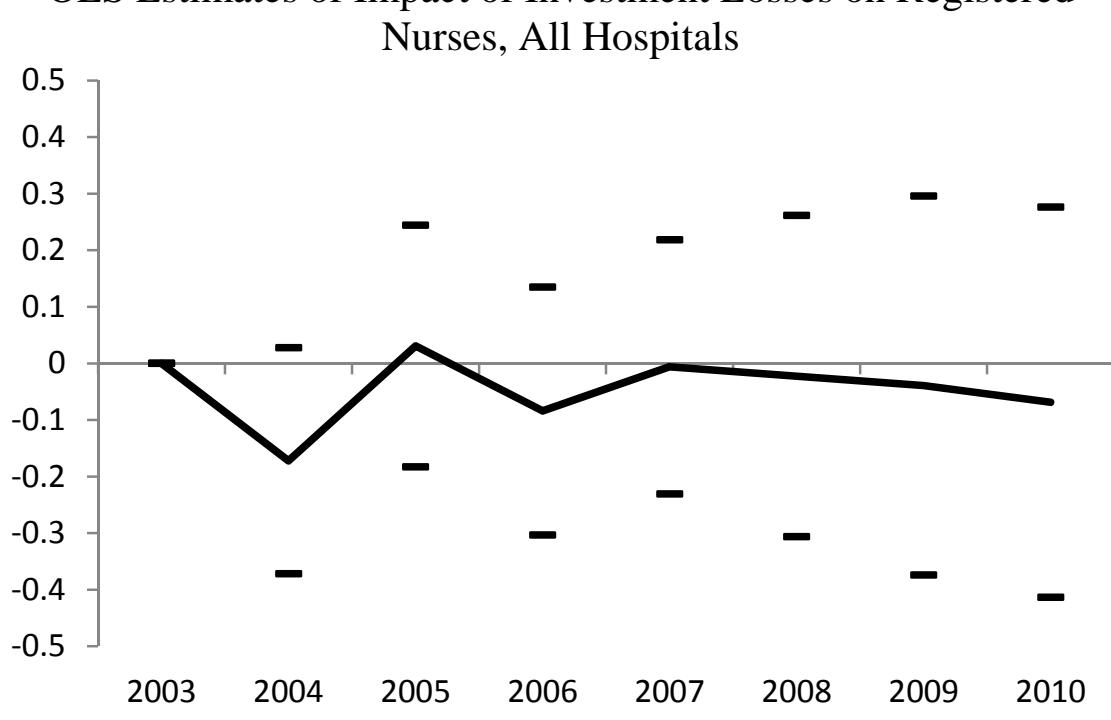

\section{Figure 6c}

OLS Estimates of Impact of Investment Losses on Licensed Practitioner Nurses, Non-System Hospitals

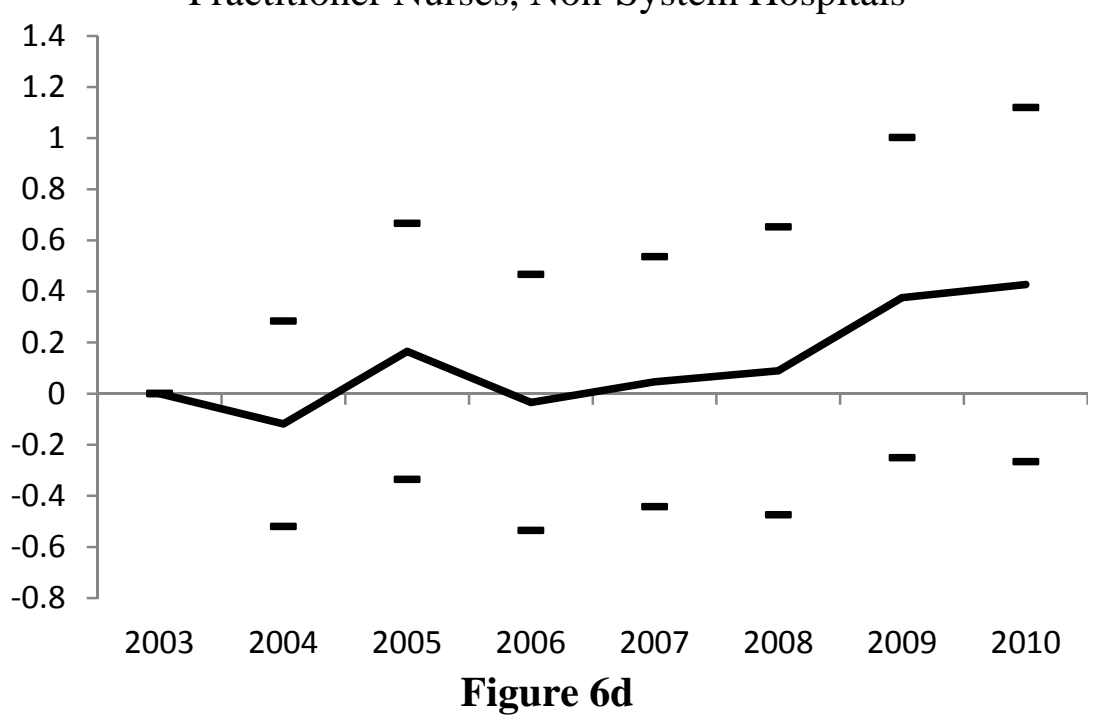

OLS Estimates of Impact of Investment Losses on Licensed Practitioner Nurses, All Hospitals

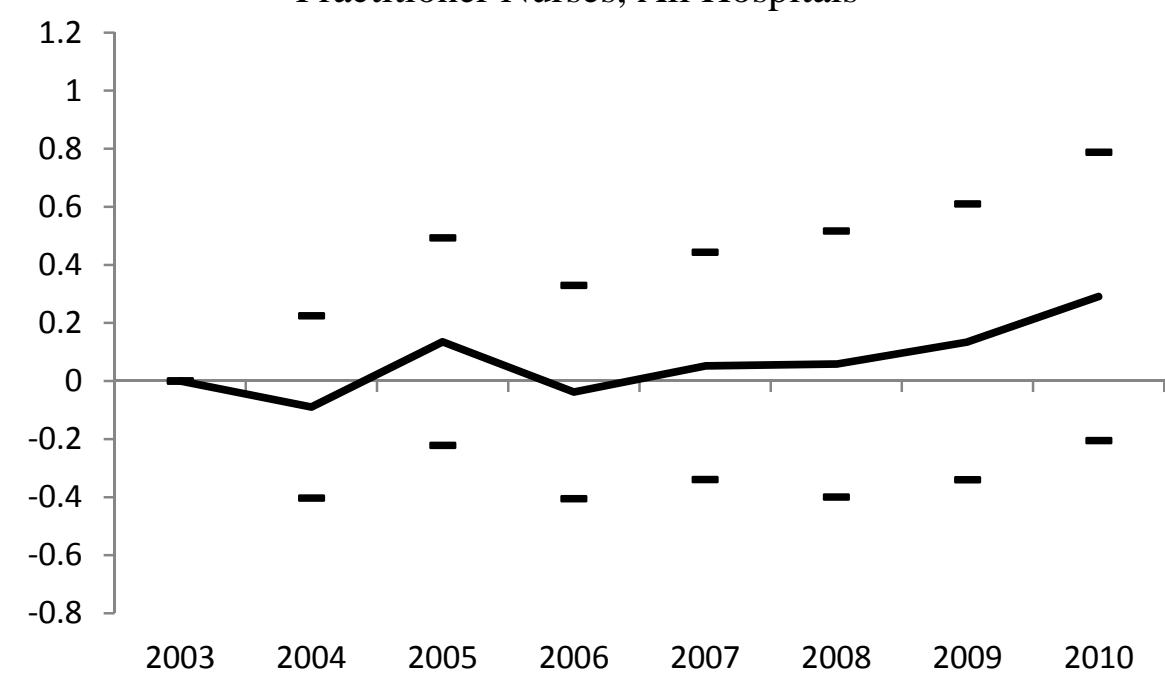


Figure 7a

OLS Estimates of Impact of Investment Losses on Trauma Centers, Non-System Hospitals

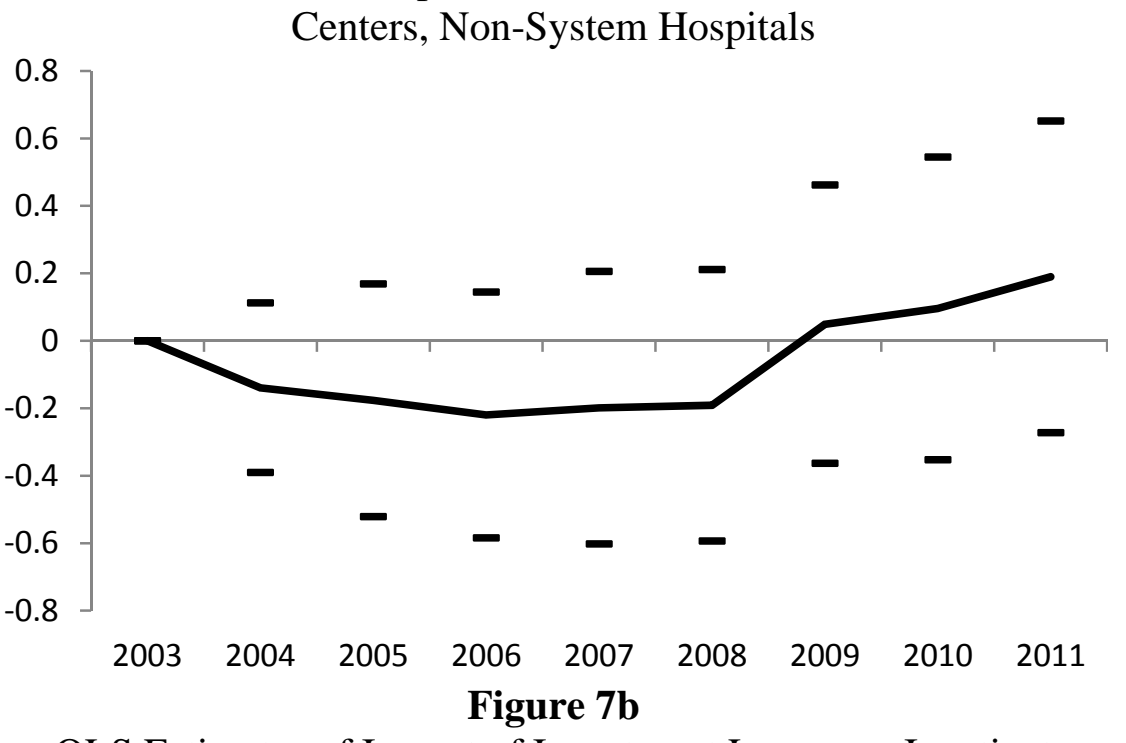

OLS Estimates of Impact of Investment Losses on Inpatient Psychiatric Services, Non-System Hospitals

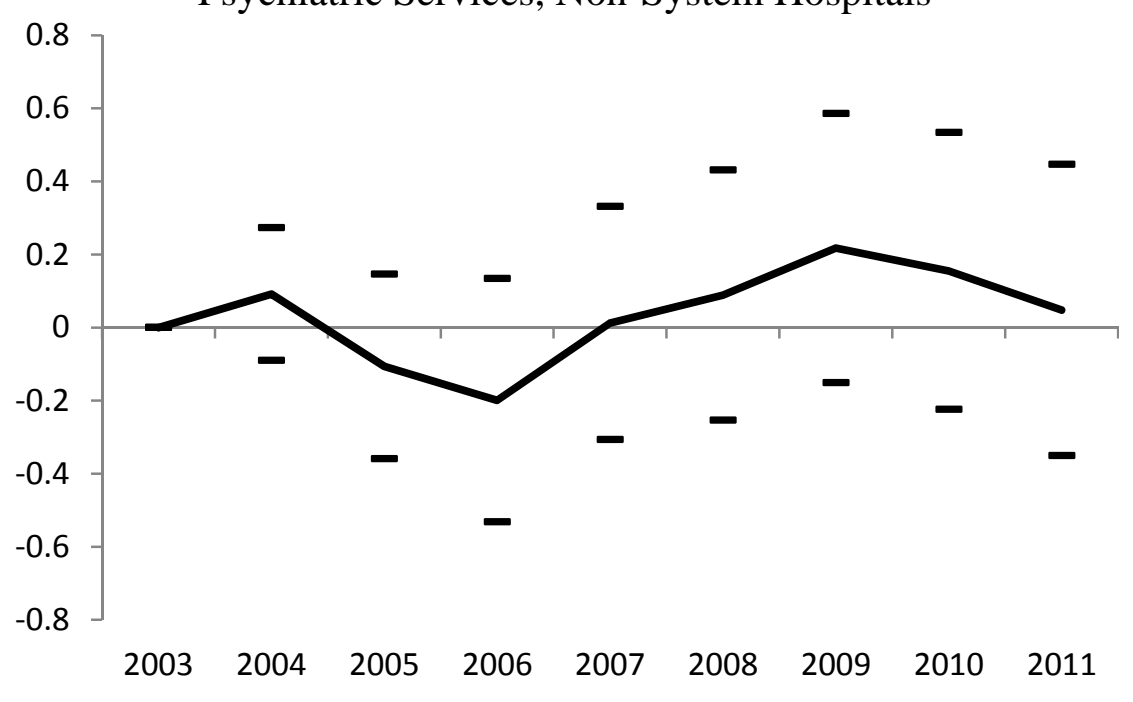

\section{Figure 7c}

OLS Estimates of Impact of Investment Losses on Inpatient Alcohol and Drug Treatment, Non-System Hospitals

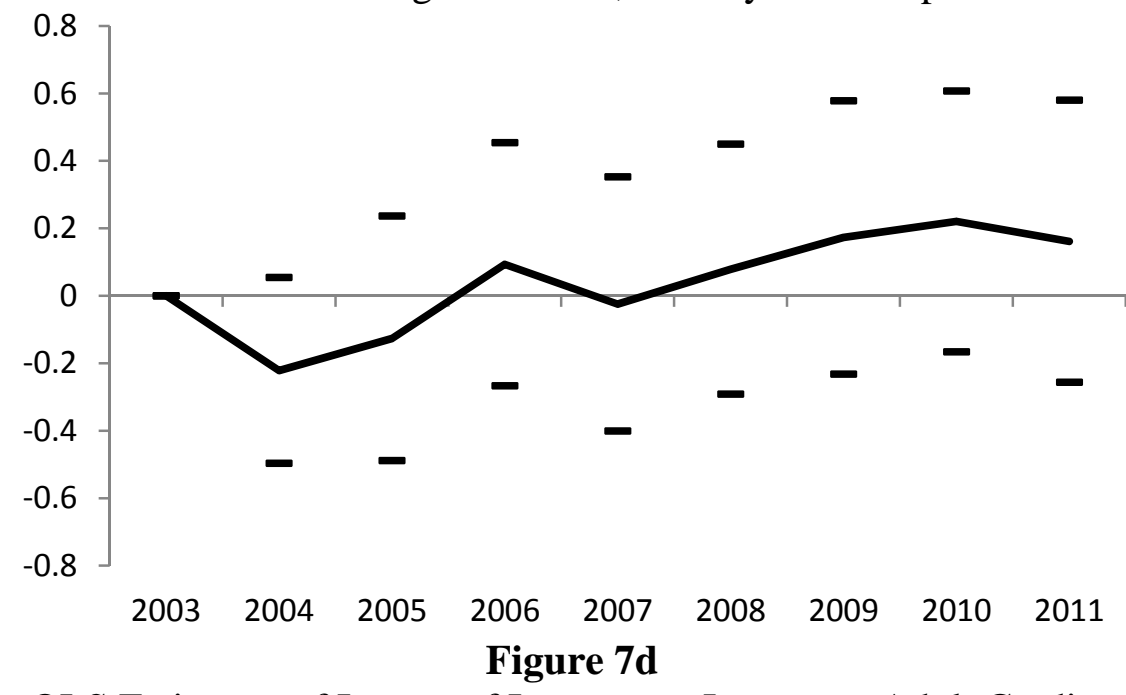

OLS Estimates of Impact of Investment Losses on Adult Cardiac Survey, for Non-System Hospitals

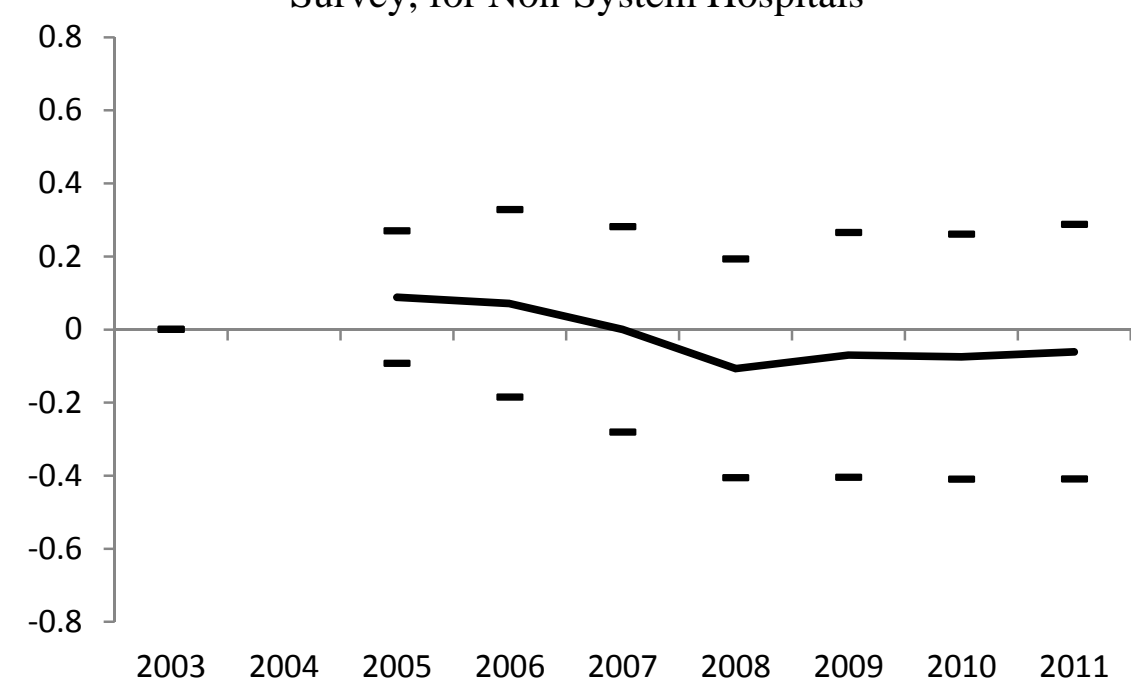


Figure 8a

OLS Estimates of Impact of Investment Losses on Trauma Centers, All Hospitals

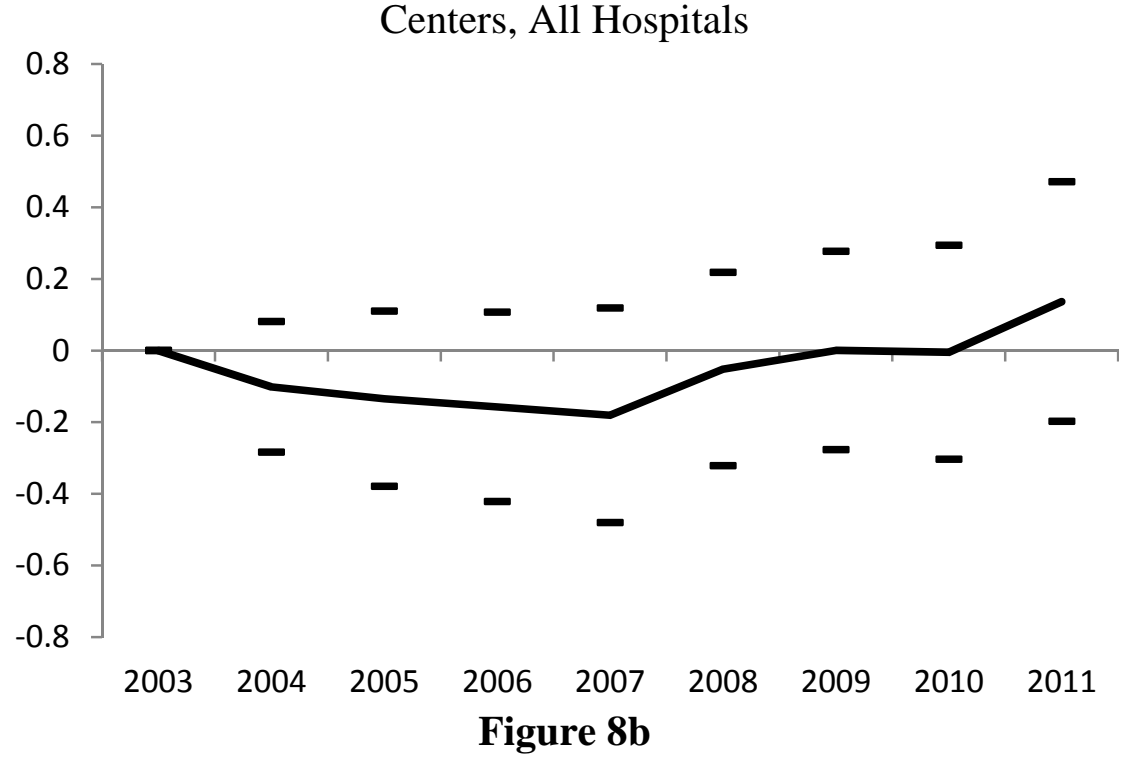

OLS Estimates of Impact of Investment Losses on Inpatient Psychiatric Services, All Hospitals

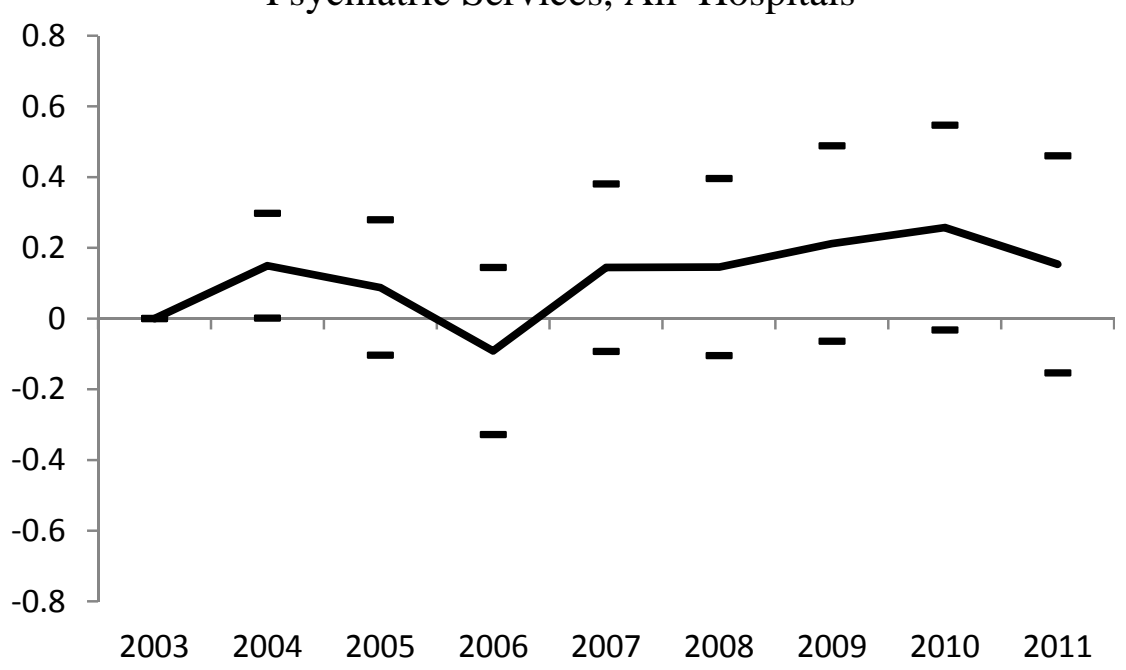

\section{Figure 8c}

OLS Estimates of Impact of Investment Losses on Inpatient Alcohol and Drug Treatment, All Hospitals

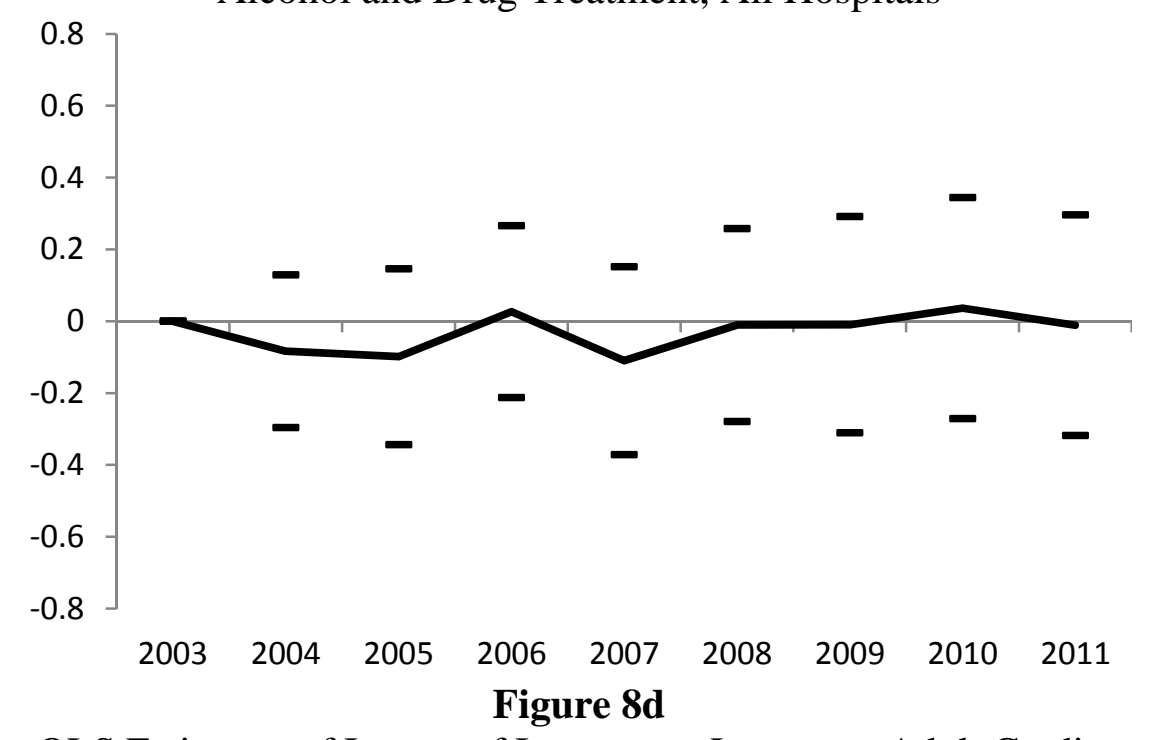

OLS Estimates of Impact of Investment Losses on Adult Cardiac Survey, for All Hospitals

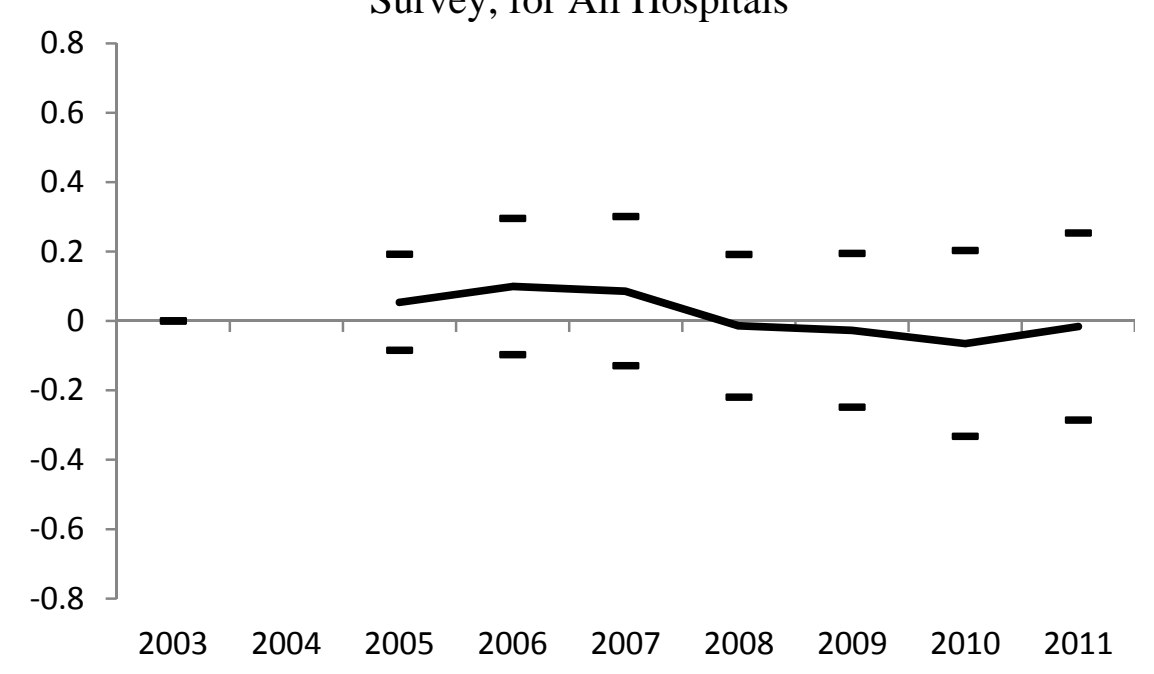




\section{References}

Ballou, Jeffrey P., and Burton A. Weisbrod. 2003. "Managerial rewards and the behavior of forprofit, governmental, and nonprofit organizations: evidence from the hospital industry”. Journal of Public Economics 83:1895-1920.

Borenstein, S. and J. Farrell 2000, “Is Cost-Cutting Evidence of X-Inefficiency?” American Economic Review, 90(2): 224-7.

Brown, Jeffrey Stephen G. Dimmock, Jun-Koo Kang. 2010. "How University Endowments Respond to Financial Shocks: Evidence and Implications.” NBER Working Paper \#15861.

Clement, J. (1997). "Dynamic cost shifting in hospitals: Evidence from the 1980s and 1990s," Inquiry, 34(4): 340-350.

Cutler, D. 1998. Cost Shifting or Cost Cutting? The Incidence of Reductions in Medicare Payments. Tax Policy and the Economy 12:1-28, J. Poterba, ed.

Dafny, L. (2009). "Estimation and Identification of Merger Effects: An Application to Hospital Mergers,” The Journal of Law \& Economics, 52, 523-550.

Dranove, D. 1988. Pricing by Non-Profit Institutions: The Case of Hospital Cost Shifting. Journal of Health Economics 7:47-57.

Dranove, D. and K. Cone (1986), "Why Did States Enact Hospital Rate Settings Laws?" Journal of Law and Economics Vol. 29

Dranove. D.. and W. White (1998). "Medicaid-dependent hospitals and their patients: How have they fared?". Health Services Research 33:163-185.

Dranove , D, C Forman, A Goldfarb, and S. Greenstein (2012). "The Trillion Dollar Conundrum: Complementarities and Health Information Technology,” NBER Working Paper \#18281

Frakt, A. (2011), “How Much do Hospitals Cost-Shift? A Review of the Evidence” Milbank Quarterly 89)1): 90-130.

Garthwaite, C. (2012). “The Doctor Might See You Now: The Supply Side Effects of Public Health Insurance Expansions,” American Economic Journal: Economic Policy 4(3): 190-215.

Gaynor, M. and R. Town, 2012, “Competition in Healthcare Markets” in Handbook of Health Economics, $2^{\text {nd }}$ Edition, McGuire, T., J. Newhouse, and P. Barros, eds., Amsterdam: Elsevier.

Gowrisankaran, G., and B. Town. 1997. Dynamic Equilibrium in the Hospital Industry. Journal of Economics \& Management Strategy 6(1):45-74.

Hand, E. 2008, “Universities Struggle as Value of Endowments Fall” Published online 31 December 2008 | Nature 457, 11-12 (2009) | doi:10.1038/457011a

Henning, Joel. 2013. “A Michigan Avenue Institution,” The Wall Street Journal, Feb 13, 2013.

Hsia RY and YC Chen (2011). "Rising closures of hospital trauma centers disproportionately burden vulnerable populations,” Health Affairs 30(10): 1912-1920. 
Health Insurance Association of America (1982) Sourcebook of Health Insurance Data, Washington, DC: 1982.

Hadley, J. and J. Feder (1985) “Hospital Cost-shifting and Care for the Uninsured” Health Affairs 4:67-80.

HIMSS Analytics. 2011. Essentials of the U.S. Hospital IT Market, $6^{\text {th }}$ Edition

Horwitz, J. 2005 “Making Profits and Providing Care: Comparing Nonprofit, For-Profit, and Government Hospitals,” Health Affairs 24-3.

Kaufman, J. 2009 “Troubles deepen for museums: layoffs, budget cuts and cancelled shows” http://www.theartnewspaper.com/articles/Troubles-deepen-for-museums-layoffs-budget-cuts-andcancelled-shows/17148 Searched 2/17/2013

Langa, K. and E. Sussman, 1993, “The Effect of Cost-containment Policies on Rates of Coronary Revascularization in California” New England Journal of Medicine 329:1784-9.

Lee, J., R. Berenson, R. Mayes, and A. Gauthier. 2003. Medicare Payment Policy: Does Cost Shifting Matter? Health Affairs, October. doi: 10.1377/hlthaff.w3.480.

Lohr, S. (2009). “Electronic Health Records: How to Spend the Money Wisely,” New York Times, Feb 102009.

Marks, Clifford and June Wu. 2008. "Harvard Endowment Fell 22 Percent in Four Months,” The Harvard Crimson, Dec 22008.

Morrisey, M. 1994. Cost Shifting in Health Care: Separating Evidence from Rhetoric. Washington, DC: AEI Press

National Federation of Independent Business v. Sebelius, No. 11-393 (slip op.) 16 (June 28, 2012).

Patient Protection and Affordable Care Act, 42 U.S.C. § 18091(2)(F).

ProPAC (1992). Optional Hospital Payment Rates. Congressional Report C-92-03.Washington, DC: U.S. Government Printing Office, 1992.

Smith, et al (various years), "Results from a 50-State Medicaid Budget Survey for State Fiscal", Kaiser Family Foundation.

Stein, J. “Internal Capital Markets and the Competition for Corporate Resources” 1997, Journal of Finance, 52(1): 111-33.

Wu, V. 2009. Hospital Cost Shifting Revisited: New Evidence from the Balanced Budget Act of 1997. International Journal of Health Care Finance and Economics, published online, August 12.

Zuckerman, S. (1987). “Commercial insurers and all-payer regulation. Evidence on hospitals' responses to financial need,” Journal of Health Economics, 6(3): 165-187.

Zwanziger, J. et al. 2000. Can Cost Shifting Continue in a Price Competitive Environment? Health Economics 9: 211-225. 


\section{ONLINE APPENDIX - NOT FOR PUBLICATION}

\section{Appendix 1: Constructing a measure of private prices}

This appendix details the construction of our estimate of private prices. Using the Hospital Cost Reports data, we construct a price per non-Medicare admission. ${ }^{33}$ This price is a weighted average of the price for private patients and for Medicaid patients. Our interest is specifically in private prices. By assuming that average Medicaid prices vary only at the state/year level, but not across hospitals within a state/year, we recover an estimated private price.

More specifically, letting $\mathrm{R}=$ total revenue, $\mathrm{P}=$ price, $\mathrm{N}=$ number of patients, $\mathrm{CMI}=$ case $\operatorname{mix}$ index, $\mathrm{r}=$ Medicare, $\mathrm{d}=$ Medicaid, $\mathrm{p}=$ private, $\mathrm{t}=$ year, $\mathrm{s}=$ state, and $\mathrm{i}=$ hospital.

$$
R_{i t}=C M I_{\text {rit }}\left(P_{\text {rit }} N_{\text {rit }}+P_{d s t} N_{\text {dit }}+P_{\text {pit }} N_{\text {pit }}\right)
$$

We observe $R_{i t}, P_{\text {rit }}, N_{\text {rit }}, N_{\text {dit }}, C M I_{\text {rit }}$ and $N_{\text {pit }}$ directly from the data. $C M I_{\text {rit }}$ is used instead of Case Mix indices for each type of patient because CMIs are only calculated by CMS for Medicare patients. Our goal is to recover $P_{\text {pit }}$. Let $\% \operatorname{priv}_{i t}$ be the percent of a facility’s non-Medicare patients with private insurance. We re-arrange to create a non-Medicare price per admission $\left(P_{-r i t}\right)$ :

$$
P_{-r i t}=P_{d s t}\left(1-\% \operatorname{priv}_{i t}\right)+P_{\text {pit }}\left(\% \operatorname{priv}_{i t}\right)
$$

This states that the CMI adjusted price per non-Medicare admission is a patient weighted average of the state level Medicaid price and hospital specific private prices. To recover an estimate of private prices, we temporarily impose the restriction that private price growth rates are the same at all facilities within a state $^{34}$ :

$$
P_{p i t}=P_{p i}\left(1+\alpha_{s t}\right)
$$

Therefore,

$$
P_{-r i t}=P_{d s t}\left(1-\% \operatorname{priv}_{i t}\right)+P_{p i}\left(1+\alpha_{s t}\right)\left(\% \operatorname{priv}_{i t}\right)
$$

We then estimate the unknowns $\left(P_{p i}, \alpha_{s t}\right.$ and $\left.P_{d s t}\right)$ using non-Medicare discharge weighted non-linear least squares. To cut on the influence of particularly large facilities, we truncate these weights at the 5\% tails by year. We impose a number of sample restrictions. First, we restrict ourselves to those facilities with non-missing CMI, price per non-Medicare discharge and discharge numbers. Second, we drop the $5 \%$ tails of price per non-Medicare discharge in each year. Finally, as facilities exiting from the data

\footnotetext{
33 The construction of this measure follows the methodology laid out in Dafny(2009) and is also used by Wu(2009).

${ }^{34}$ For some states, our estimation sample is too small for us to separately identify a private price trend and a Medicaid trend (or, if technically identified, the objective function is too flat). We pair these states up with a neighboring state, forcing the private trend to be the same. The grouped states are North Dakota/South Dakota, DC/Delaware/Maryland, New Hampshire/Vermont, Connecticut/Rhode Island and Idaho/Montana. We drop Alaska and Hawaii.
} 
exhibit different time trends, as well as to cut down on the number of parameter estimates, we restrict ourselves to facilities present in at least 9 of the 13 years of data.

Neither private prices, nor Medicaid prices are observed. We are able to identify the relative growth in private prices vs Medicaid prices by looking at how growth in revenues per patient varies with the percent of a hospital's non-Medicare patients with have private insurance. Identification of the hospital specific private price intercept is less clear. In particular, if a hospital has more private patients and higher prices, this suggests that private prices must be high at this specific hospital.

Using the recovered estimates of Medicaid prices, we construct private prices estimates as:

$$
P_{p i t}=\frac{P_{-r i t}-\hat{P}_{d i t}\left(1-\% \operatorname{priv}_{i t}\right)}{\% \operatorname{priv}_{i t}}
$$

